\title{
Probing orographic controls in the Himalayas during the monsoon using satellite imagery
}

\author{
A. P. Barros ${ }^{1}$, G. Kim ${ }^{2}$, E. Williams ${ }^{1}$, and S. W. Nesbitt ${ }^{3}$ \\ ${ }^{1}$ Division of Engineering and Applied Sciences, Harvard University, USA \\ ${ }^{2}$ Department of Civil Engineering, Kyungpook National University, Korea \\ ${ }^{3}$ Department of Meteorology, University of Utah, USA
}

Received: 5 November 2002 - Revised: 30 June 2003 - Accepted: 20 November 2003 - Published: 1 March 2004

\begin{abstract}
The linkages between the space-time variability of observed clouds, rainfall, large-circulation patterns and topography in northern India and the Himalayas were investigated using remote sensing data. The research purpose was to test the hypothesis that cloudiness patterns are dynamic tracers of rainstorms, and therefore their temporal and spatial evolution can be used as a proxy of the spatial and temporal organization of precipitation and precipitation processes in the Himalayan range during the monsoon. The results suggest that the space-time distribution of precipitation, the spatial variability of the diurnal cycle of convective activity, and the terrain (landform and altitudinal gradients) are intertwined at spatial scales ranging from the order of a few $\mathrm{kms}(1-5 \mathrm{~km})$ up to the continental-scale. Furthermore, this relationship is equally strong in the time domain with respect to the onset and intra-seasonal variability of the monsoon.

Infrared and microwave imagery of cloud fields were analyzed to characterize the spatial and temporal evolution of mesoscale convective weather systems and short-lived convection in Northern India, the Himalayan range, and in the Tibetan Plateau during three monsoon seasons (1999, 2000 and 2001). The life cycle of convective systems suggests landform and orographic controls consistent with a convergence zone constrained to the valley of the Ganges and the Himalayan range, bounded in the west by the Aravalli range and the Garhwal mountains and in the East by the Khasi Hills and the Bay of Bengal, which we call the Northern India Convergence Zone (NICZ). The NICZ exhibits strong nighttime activity along the south-facing slopes of the Himalayan range, which is characterized by the development of shortlived convection $(1-3 \mathrm{~h})$ aligned with protruding ridges between 1:00 and 3:00 AM. The intra-annual and inter-annual variability of convective activity in the NICZ were assessed with respect to large-scale synoptic conditions, monsoon activity in the Bay of Bengal, and the modulating role of orography. Empirical orthogonal function (EOF) and canoni-
\end{abstract}

Correspondence to: A. P. Barros

(barros@deas.harvard.edu) cal correlation (CC) analysis suggest that joint modes of variability of monsoon weather and topography, which we call orographic land-atmosphere interactions, modulate the space-time variability of cloudiness in the region. Finally, scaling analysis of cloudiness suggests three different scaling regimes of orographic land-atmosphere interactions:

1) a synoptic-scale regime ( $\geq 70-80 \mathrm{~km}) ; 2)$ an orographic meso $-\beta$ regime $(30-70 \mathrm{~km})$ associated with the succession of wide valleys and bulky terrain features; and 3 ) an orographic meso $-\alpha$ regime $(\leq 30 \mathrm{~km})$ associated with the complex succession of protruding south-facing ridges and narrow valleys that characterize the Himalayan foothills between altitudes of 3000 and $5000 \mathrm{~m}$ elevations.

\section{Introduction}

The Himalayan range at the southern edge of the Tibetan Plateau is uniquely placed to modulate the regional monsoon climate in northern India (Fig. 1). Many studies over the last 30 years focused on investigating the large-scale modes of variability of the Asian monsoon climate with respect to the role of the Tibetan Plateau (e.g. Hahn and Manabe, 1975; Murakami 1987, 1983; Webster 1987; and many others). On seasonal and inter-annual time-scales, the monsoon season in the Himalayas provides a stage where rapid environmental change and extreme events (floods, landslides) occur on schedule, and thus a natural laboratory where vigorous interactions among climate, geomorphology and hydrology can be studied in real time.

From a geomorphology perspective, the challenge is to determine how regional variations in climate affect orogenic evolution. Precipitation processes (snow and rainfall) are the physical mechanisms by which these interactions are triggered and sustained. That is, the spatial and temporal variability of precipitation (location, amount and intensity) and runoff response drive the space-time variability of surface change across the landscape. The overarching goal of our research is to elucidate the space-time modes of variability of 


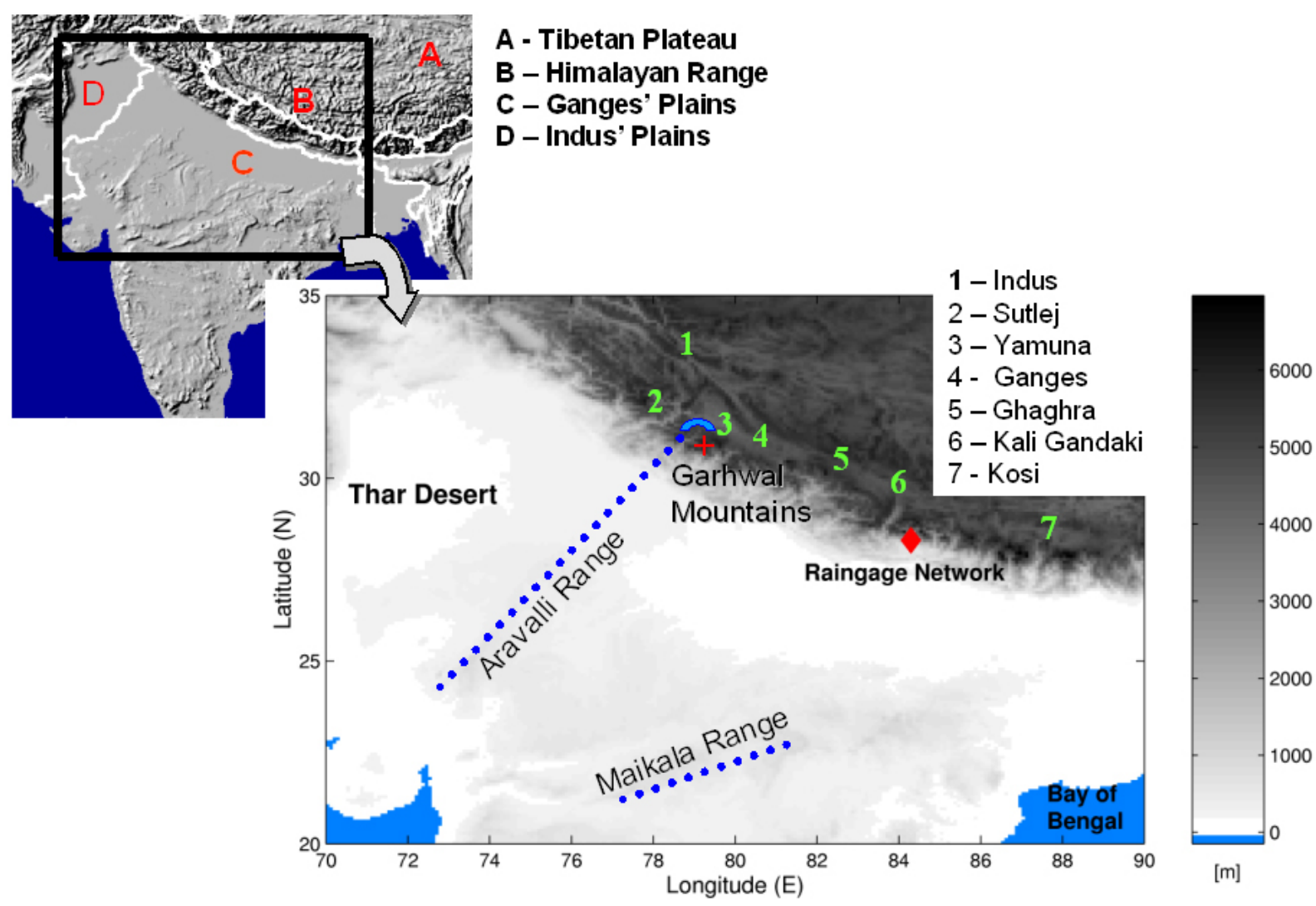

Fig. 1. Map and Digital Elevation Model (DEM) of the region of study. Large rivers are marked with numbers corresponding to the names in the legend. Relevant topographic features are also marked, as well as the location of the hydrometeorological network in central Nepal.

precipitation in the southern facing slopes of the Himalayas. Here, we focus on identifying the spatial and temporal scales at which landform interacts with monsoon weather, and thus determines the spatial organization of precipitation processes and precipitation fields regionally.

\section{Statement of the problem}

In the southern-facing slopes of the Himalayas, the signature of the monsoon is most readily associated with the summer rainy season, which accounts for about $90 \%$ and $60 \%$ of the annual rainfall at low $(\leq 3000 \mathrm{~m})$ and high elevations, respectively (Barros et al., 2000). During the monsoon onset, heavy precipitation events in the Himalayas are associated with relatively organized shallow convection at the foothills of southfacing slopes and valleys brought by mesoscale depressions originating in the Bay of Bengal (Lang and Barros, 2002). Along the Himalayan range, convective cells appear embedded in large areas of persistent stratiform rainfall, which occur over elevations of 5000-6000 m and exhibit a leadingline-trailing stratiform MCS-type structure. The hydroclimatology of precipitation from Nepalese raingauges along river valleys across the Himalayan range suggests orographic precipitation enhancement factors ranging from $200 \%$ up to 300\% (Nepal Department of Hydrology and Meteorology,
Climate Summaries). An analysis of a 3-year data set from a high-elevation hydrometeorological network in central Nepal (Barros et al., 2000) confirms these estimates and shows that annual precipitation amounts up to $5000 \mathrm{~mm}$ occur at elevations up to $4500 \mathrm{~m}$ on protruding ridges. Furthermore, the observations suggest that not only elevation, but especially the spatial arrangement of topographic gradients determine precipitation patterns (Fig. 2) including: 1) weak altitudinal gradients of annual rainfall between 1000 and about $4500 \mathrm{~m}$; 2) strong ridge-to-ridge zonal (east-west) gradients of monsoon rainfall $(1500 \mathrm{~mm} / 5 \mathrm{~km})$; 3) strong ridge-valley gradients during rainstorms, especially in the case of deep valleys (elevation differences $\geq 1000 \mathrm{~m}$ ) and steep slopes $(70 \%)$; and 4) strong altitudinal gradients in rainfall intensity and duration (convective versus stratiform), with longer (shorter) durations and lower (higher) intensities at high (low) elevations along the ridges.

Locally, the analysis of the time series of rainfall shows that all stations, and especially ridge locations, exhibit a strong nocturnal peak between 10:00 PM and midnight followed by more intense, short downpours between 1:00 and 3:00 AM LST (Barros et al., 2000, Fig. 3). The persistence and even intensification of this nocturnal peak between 1:00 and 3:00 AM is hypothesized to result from a low-level convergence zone on windward valley slopes, enhanced by evaporative cooling of rainfall early in the night (first nocturnal 


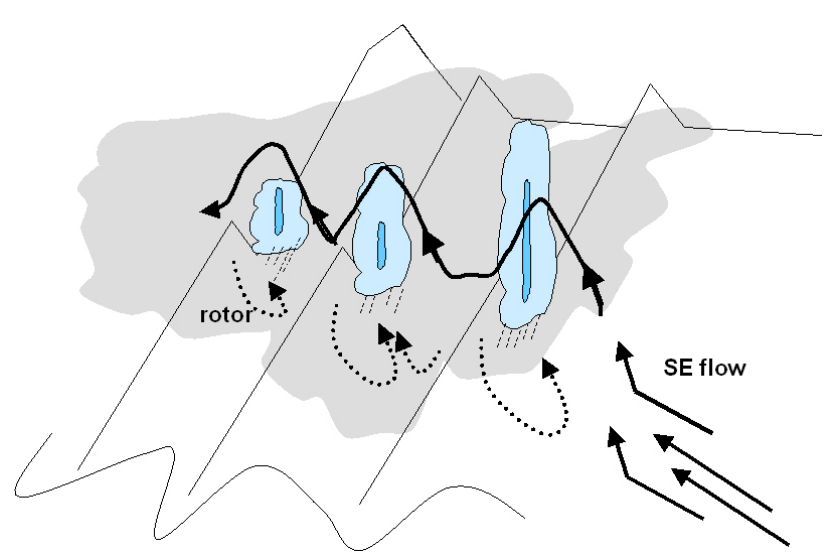

Fig. 2. Conceptual summary of the spatial distribution of rainfall obtained in model simulations for typical monsoon forcing as per Barros and Lang (2003b). (Continuous dark lines represent orographic gravity waves; dashed lines represent single-cell mountainvalley circulations.)

peak) and evapotranspiration from dense vegetation below $3000 \mathrm{~m}$ (see for example Murakami, 1987). The thermodynamic profiles obtained from soundings launched during MOHPREX (Monsoon Himalaya Precipitation Experiment) in June 2001 support the observed nocturnal maximum in rainfall during the monsoon, with total column moisture and instability maximized just before rainfall peaks (Barros and Lang, 2003a). Note that due to the complexity of the local orography, interactions between the upper-level flow, orographic gravity waves, and boundary-layer daytime heating and nighttime cooling all influence the relative location of these stations with respect to the envelope topography. Barros and Lang (2003b), using a cloud resolving model (CRM) at roughly $2 \mathrm{~km}$ spatial resolution, showed that vertical motion cells formed band-like structures that remained largely stationary with time, with updrafts on the leewind slopes and downdrafts over upwind slopes and ridges. Diurnal sensible heating input in the boundary layer strengthened upward flows in the lower troposphere and tended to strengthen anticlockwise single-cell circulations between upwind slopes and valley bottoms.

To generalize these findings, we adopt here the strategy of using cloudiness fields as a proxy of rain-producing weather to characterize the predominant regimes of convective mesoscale interactions with steep terrain forcing. That is, cloudiness is used as a dynamic tracer of the space-time variability of rainfall. For this purpose, we use high resolution infrared and microwave remotely sensed data from Meteosat-5 and TRMM (Tropical Rainfall Measuring Mission) satellites. Our objective is not only to quantify and describe the spatial patterns of the monsoon hydroclimatology with respect to landform, but also to establish linkages between these modes of variability and the large-scale circulation modes of the monsoon, in order to infer physically based

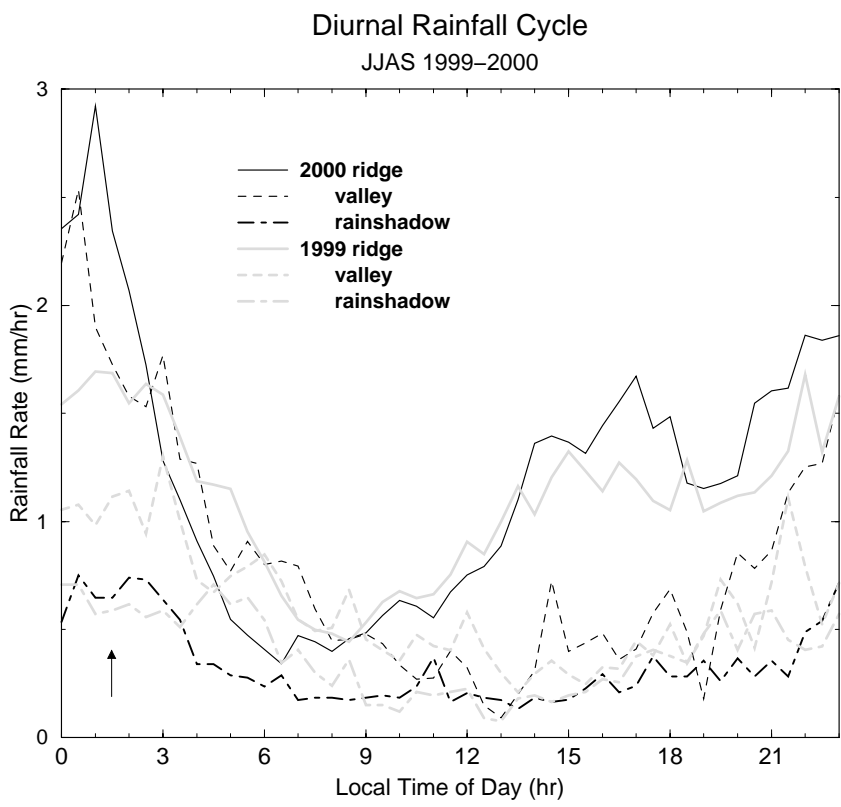

Fig. 3. Average diurnal cycle of rainfall for the entire monsoon season (JJAS - June, July, August, and September) for 1999 and 2000. Observations are from the hydrometeorological network described by Barros et al. (2000). Note that despite interannual variability, the overall pattern is the same from one year to the next. Especially relevant is the difference between the diurnal cycle at high (nocturnal rainfall peak between midnight and 3 AM marked with black arrow) and low elevations (with afternoon and evening rainfall peaks).

diagnostic relationships between monsoon weather and the space-time variability of monsoon rainfall.

To accomplish this objective, we focus first on elucidating the life cycle of convective systems and their spatial trajectories. Second, we explore the linkages between the evolution patterns of cloud fields, monsoon forcing, and organized convective activity at the synoptic scale. Finally, we demonstrate that over the Himalayan range the space-time modes of variability of cloud fields are consistent with the orographic modification of monsoon forcing at various scale ranges as inferred from the CRM simulations (Barros and Lang, 2003b).

\section{Characterization of precipitation features and con- vective activity using remote sensing}

After the concept of Mesoscale Convective Complex (MCC) was first introduced by Maddox (1980), several studies focused on characterizing the climatology of MCCs for different regions of the world using remote sensing data at various resolutions. Systematic relationships between orography and the development of MCCs were identified by Laing and Fritsch (1997) globally, by Augustine and Howard (1991) in North America, and by Mathon and Laurent (2001) in northwest Africa.

Convective activity is ubiquitous along the Himalayan range. Figure 4 a shows the spatial variability of the monthly 


\section{Lightning Activity - 1999}
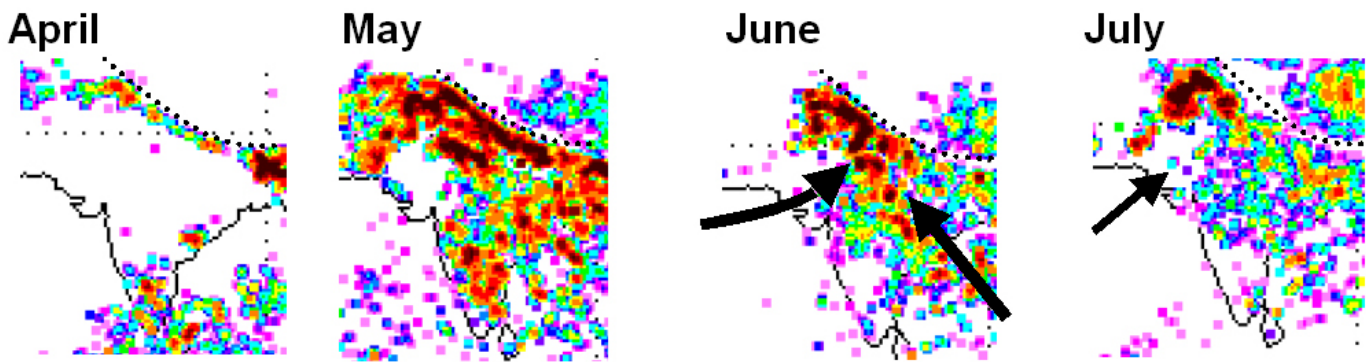

\section{$\begin{array}{llllllllll}1 & 2 & 3 & 4 & 5 & >5 & >10 & >15 & >25 & >50>100>150\end{array}$}

\section{$\square \square \square \square L$}

August

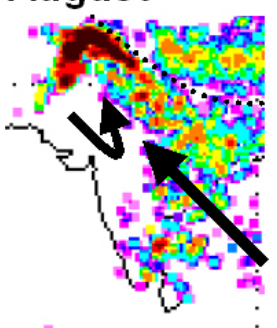

October

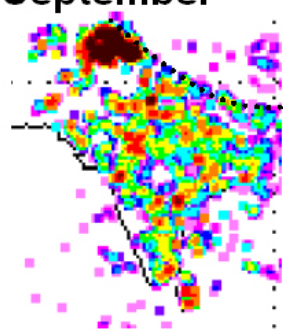

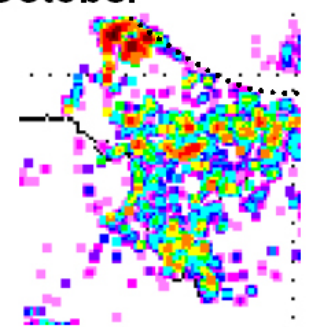

November

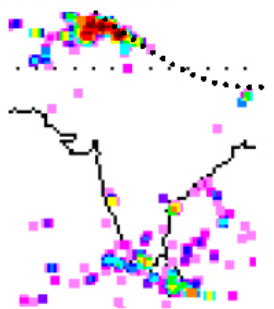

(a)

\section{0 hPa Patterns}

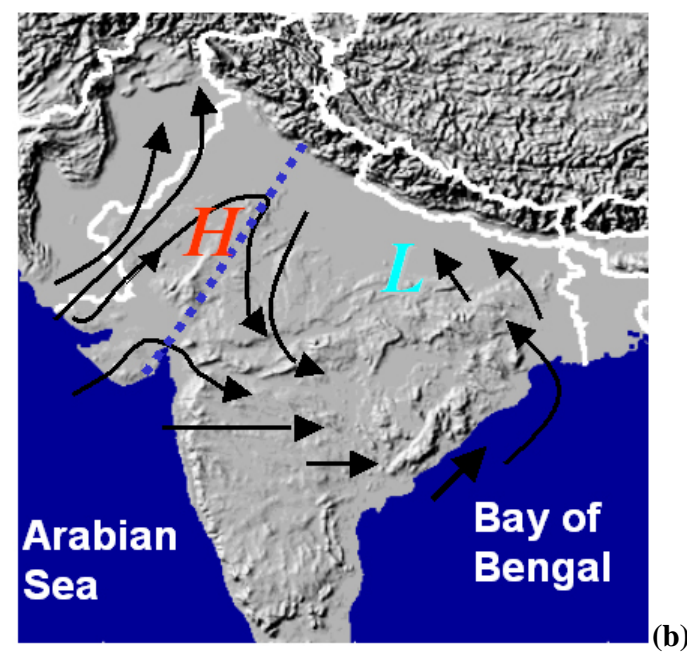

1999 ONSET

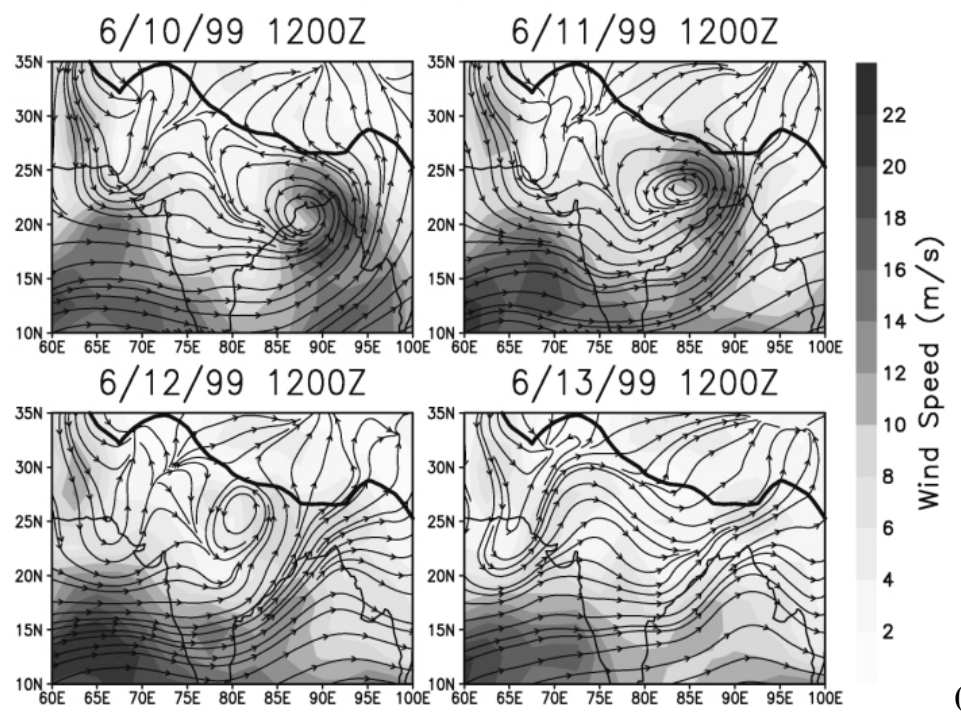

(c)

Fig. 4. (a) Monthly composites of lightning activity as measured by flash rates from April to November; (b) conceptual depiction of major synoptic-scale circulations over the north Indian subcontinent during the monsoon (after Murakami, 1999) (L - low pressure center; H - high pressure center); (c) time sequence of daily ECMWF analysis showing $850 \mathrm{hPa}$ wind streamlines and speed on $10 \mathrm{June} 1999$ at the time of monsoon onset (Lang and Barros 2002). 
Table 1. Definitions of the basic characteristics of convective weather systems used in the analysis and interpretation of Meteosat-5 cloud imagery.

\begin{tabular}{|c|c|}
\hline \multicolumn{2}{|c|}{ Mesoscale Convective Complex (MCC) } \\
\hline $\begin{array}{l}\text { Size: } \\
\text { Shape: } \\
\text { Duration: }\end{array}$ & $\begin{array}{l}\text { Cloud shield which has continuously low IR temperature of less than } 219 \mathrm{~K} \text { with area }>50000 \mathrm{~km}^{2} \\
\text { Eccentricity (minor axis/major axis) }>0.7 \\
\text { Size definitions last for a period }>6 \mathrm{~h}\end{array}$ \\
\hline \multicolumn{2}{|c|}{ Convective Cloud Cluster (CCC) } \\
\hline $\begin{array}{l}\text { Size: } \\
\text { Shape: } \\
\text { Duration: }\end{array}$ & $\begin{array}{l}\text { Cloud shield which has continuously low IR temperature of less than } 219 \mathrm{~K} \text { with area }>4000 \mathrm{~km}^{2} \\
\text { No shape criterion } \\
\text { Size definitions last for a period }>6 \mathrm{~h}\end{array}$ \\
\hline \multicolumn{2}{|c|}{ Disorganized Short-lived Convection (DSC) } \\
\hline $\begin{array}{l}\text { Size: } \\
\text { Shape: } \\
\text { Duration: }\end{array}$ & $\begin{array}{l}\text { Cloud shield which has continuously low IR temperature of less than } 219 \mathrm{~K} \text { must area }>4000 \mathrm{~km}^{2} \\
\text { No shape criterion } \\
\text { Size definitions last for a period }<6 \mathrm{~h}\end{array}$ \\
\hline
\end{tabular}

distribution of lightning flashes in the Indian subcontinent from the Lightning Imaging Sensor (LIS; Christian et al., 1999) on the TRMM platform (http://www.ghcc.msfc.nasa. gov) during eight months (April-November) in 1999. Lightning can be used as a proxy of deep convection in a very unstable atmosphere (e.g. Petersen et al., 1996); therefore, the LIS data can be used as a space-time index of convective activity. Note how convective activity extends to the entire Indian subcontinent during the monsoon months (MayOctober), and how it recedes and weakens from November until March. More importantly, the high intensity pattern that follows the topographic envelope in May is pushed toward the Hindu Kush mountains in the NW corner of Pakistan during the monsoon proper, with much lower flash rates observed elsewhere. Especially remarkable is the lack of convective activity over the Thar Desert, in the western slopes of the Aravalli range. These spatial features are consistent with previous studies of synoptic-scale monsoon circulations in the region: 1) the role of the Aravalli range in separating western, drier and more unstable air masses from moist and relatively stable air masses from the Bay of Bengal (Fig. 4b; Murakami et al., 1999); and 2) the detection of shallow embedded convection only over the central Himalayas during TRMM PR (Precipitation Radar) overpasses (Lang and Barros, 2002; Barros and Lang, 2003a).

\subsection{Infrared data and methodology}

Infrared satellite imagery from Meteosat- 5 was examined to describe the life cycles and meteorological characteristics of convective weather systems in the Himalayan range during the monsoon. In this work, we used hourly infrared (IR) imagery (channel 8) with spatial resolution of roughly $10 \mathrm{~km}$ over an area defined by $\left(20-35^{\circ} \mathrm{N}, 70-90^{\circ} \mathrm{E}\right)$. Brightness temperature (BT), latitude and longitude data for each satellite image pixel were obtained from IR images using the Man Computer Interactive Data Access System (MCIDAS, orig- inally developed at the University of Wisconsin and maintained at the National Center for Atmospheric Research). Missing data (fewer than $4 \%$ of total) were replaced using bi-linear interpolation.

An algorithm modified after Evans and Shemo (1996) was used to detect the presence and monitor the evolution of MCCs, CCCs (convective cloud clusters), and DSCs (disorganized short-lived convective clouds) during the monsoon season (June through September) according to size, shape, and lifetime criteria as summarized in Table 1. The algorithm estimates the lifetime, area, temperature, eccentricity and centroid position of the $219 \mathrm{~K}$ and $235 \mathrm{~K}$ cold cloud shields associated with deep convection. The evolution of areal extent and eccentricity values were monitored to determine the duration and lifetime of the convective weather systems (CWSs), while the centroid positions were used to determine their propagation characteristics. Note that the MCC definition adopted here was modified after Maddox (1980). Specifically, if the shape criterion of MCC is met at the maximum extent during its previous or next time step (i.e. 1-hour difference), we classify the weather system as MCC. In addition, when the MCC shape criterion is met within $80 \%$ of maximum extent during the evolution of individual MCCs, the weather system is still classified as MCC. If CWSs do not satisfy the MCC criteria of areal extent and shape, but last more than $6 \mathrm{~h}$ with smaller area criterion $\left(>4000 \mathrm{~km}^{2}\right)$, they are classified as CCCs. If the areal extent of cold cloud shield satisfies the area criterion $\left(>4000 \mathrm{~km}^{2}\right)$ but the duration does not exceed $6 \mathrm{~h}$, then the CWSs are classified as DSCs.

A summary of the characteristics (and relative frequency) of MCCs (10s), CCCs (100s) and DSCs (1000s) is provided in Tables 2, 3, and 4, respectively, for 1999 and 2000. The most important differences between the two years occur during July at the peak of convective activity (higher in 1999 than in 2000) and in September during the retreat of the monsoon (slower in 2000 than in 1999) consistently with the 
Table 2. Statistical summary of the characteristics of MCCs.

\begin{tabular}{|c|c|c|c|c|c|c|c|c|}
\hline & \multicolumn{2}{|c|}{ June } & \multicolumn{2}{|c|}{ July } & \multicolumn{2}{|c|}{ August } & \multicolumn{2}{|c|}{ September } \\
\hline & 1999 & 2000 & 1999 & 2000 & 1999 & 2000 & 1999 & 2000 \\
\hline Number of MCCs & 9 & 9 & 19 & 11 & 8 & 8 & 5 & 6 \\
\hline Life Time (h) & 11.2 & 11.6 & 10.5 & 10.8 & 9.8 & 10.8 & 12.5 & 10.3 \\
\hline Average Area $<219 \mathrm{~K}\left(\mathrm{~km}^{2}\right)$ & 151180 & 131204 & 129389 & 124678 & 98035 & 89522 & 100793 & 121915 \\
\hline Stdv. of Area $<219 \mathrm{~K}\left(\mathrm{~km}^{2}\right)$ & 53462 & 33979 & 40604 & 35817 & 47050 & 17315 & 28258 & 30402 \\
\hline Average Temp. (K) & 205.3 & 207.2 & 207.9 & 208.3 & 208.4 & 206.6 & 208.3 & 208.1 \\
\hline Stdev. of Temp. (K) & 7.4 & 6.5 & 6.4 & 6.1 & 6.2 & 6.5 & 6.3 & 6.4 \\
\hline Average Area $<235 \mathrm{~K}\left(\mathrm{~km}^{2}\right)$ & 311634 & 286230 & 310710 & 243928 & 194774 & 189198 & 199507 & 247033 \\
\hline Stdv. of Area $<235 \mathrm{~K}\left(\mathrm{~km}^{2}\right)$ & 95387 & 90416 & 117217 & 75729 & 107753 & 60371 & 58394 & 51612 \\
\hline Average Temp. (K) & 213.0 & 215.4 & 215.5 & 215.5 & 214.7 & 213.7 & 215.8 & 215.8 \\
\hline Stdev. of Temp. (K) & 11.7 & 10.9 & 10.4 & 10.2 & 10.1 & 10.9 & 10.6 & 10.7 \\
\hline
\end{tabular}

Table 3. Statistical summary of the characteristics of CCCs.

\begin{tabular}{|c|c|c|c|c|c|c|c|c|}
\hline & \multicolumn{2}{|c|}{ June } & \multicolumn{2}{|c|}{ July } & \multicolumn{2}{|c|}{ August } & \multicolumn{2}{|c|}{ September } \\
\hline & 1999 & 2000 & 1999 & 2000 & 1999 & 2000 & 1999 & 2000 \\
\hline Number of CCCs & 90 & 134 & 209 & 214 & 203 & 188 & 154 & 91 \\
\hline Life Time (h) & 7.9 & 7.7 & 7.7 & 7.9 & 7.7 & 7.6 & 8.0 & 7.8 \\
\hline Average Area $<219 \mathrm{~K}\left(\mathrm{~km}^{2}\right)$ & 42728 & 35989 & 37149 & 34554 & 39056 & 35883 & 32518 & 29131 \\
\hline Stdv. of Area $<219 \mathrm{~K}\left(\mathrm{~km}^{2}\right)$ & 26302 & 22753 & 21692 & 22029 & 22128 & 20463 & 16866 & 13538 \\
\hline Average Temp. (K) & 209.6 & 210.5 & 210.6 & 211.4 & 210.5 & 210.7 & 210.4 & 211.3 \\
\hline Stdev. of Temp. (K) & 5.6 & 5.0 & 5.1 & 4.6 & 5.3 & 5.1 & 5.1 & 4.7 \\
\hline Average Area $<235 \mathrm{~K}\left(\mathrm{~km}^{2}\right)$ & 154413 & 136542 & 187432 & 178914 & 166194 & 152921 & 113936 & 99959 \\
\hline Stdv. of Area $<235 \mathrm{~K}\left(\mathrm{~km}^{2}\right)$ & 70776 & 74344 & 108509 & 93667 & 84102 & 76696 & 56548 & 40289 \\
\hline Average Temp. (K) & 217.2 & 218.1 & 218.0 & 218.9 & 217.5 & 218.0 & 218.1 & 219.0 \\
\hline Stdev. of Temp. (K) & 10.0 & 9.3 & 9.3 & 8.7 & 9.5 & 9.3 & 9.3 & 8.9 \\
\hline
\end{tabular}

Table 4. Statistical summary of the characteristics of DSCs.

\begin{tabular}{|c|c|c|c|c|c|c|c|c|}
\hline & \multicolumn{2}{|c|}{ June } & \multicolumn{2}{|c|}{ July } & \multicolumn{2}{|c|}{ August } & \multicolumn{2}{|c|}{ September } \\
\hline & 1999 & 2000 & 1999 & 2000 & 1999 & 2000 & 1999 & 2000 \\
\hline Number of DSCs & 1098 & 1247 & 1902 & 2416 & 2,270 & 1950 & 1436 & 920 \\
\hline Life Time (h) & 1.9 & 2.0 & 2.0 & 2.0 & 1.9 & 2.0 & 2.0 & 1.9 \\
\hline Average Area $<219 \mathrm{~K}\left(\mathrm{~km}^{2}\right)$ & 20550 & 17577 & 18644 & 18441 & 19071 & 18447 & 15487 & 14630 \\
\hline Stdv. of Area $<219 \mathrm{~K}\left(\mathrm{~km}^{2}\right)$ & 4203 & 4584 & 4400 & 4367 & 4100 & 4614 & 3263 & 2794 \\
\hline Average Temp. (K) & 211.4 & 211.8 & 212.1 & 212.8 & 211.9 & 212.0 & 212.0 & 212.7 \\
\hline Stdev. of Temp. (K) & 4.6 & 4.3 & 4.3 & 3.9 & 4.5 & 4.4 & 4.2 & 4.0 \\
\hline Average Area $<235 \mathrm{~K}\left(\mathrm{~km}^{2}\right)$ & 123513 & 125012 & 181130 & 172857 & 167889 & 143368 & 123822 & 96324 \\
\hline Stdv. of Area <235 K $\left(\mathrm{km}^{2}\right)$ & 20144 & 23218 & 33528 & 32884 & 26824 & 29274 & 19304 & 15685 \\
\hline Average Temp. (K) & 218.4 & 219.0 & 218.5 & 219.4 & 218.7 & 218.4 & 219.4 & 219.6 \\
\hline Stdev. of Temp. (K) & 9.3 & 8.9 & 8.9 & 8.3 & 9.0 & 8.9 & 8.7 & 8.3 \\
\hline
\end{tabular}



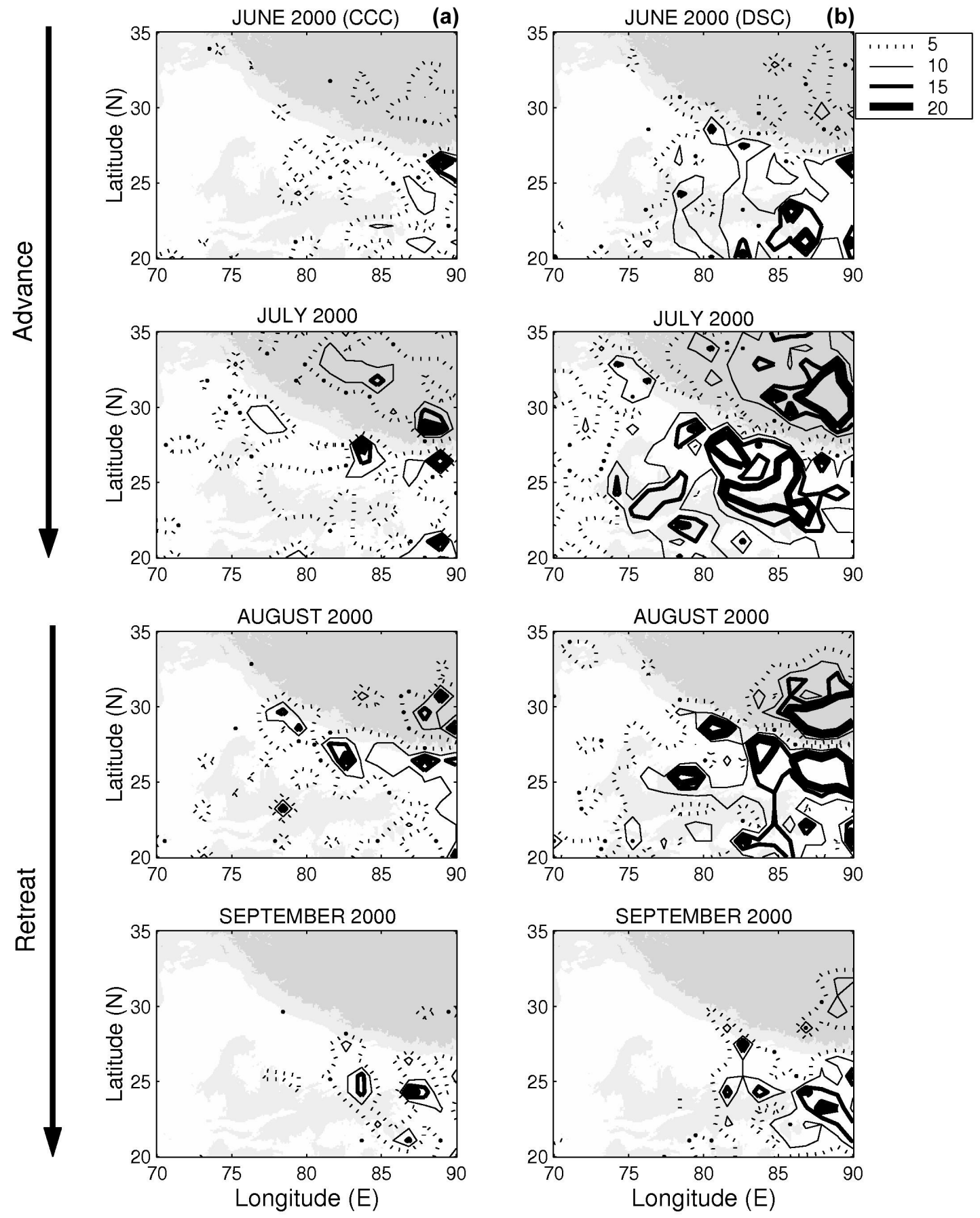

Fig. 5. Monthly contour plots of the frequency distributions of CWSs: (a) convective cloud clusters (CCCs); and (b) disorganized short-lived convection centers (DSCs) during the 2000 monsoon season. Detailed description of the criteria and CWSs' properties are presented in Tables 1 through 4 . 
(a)

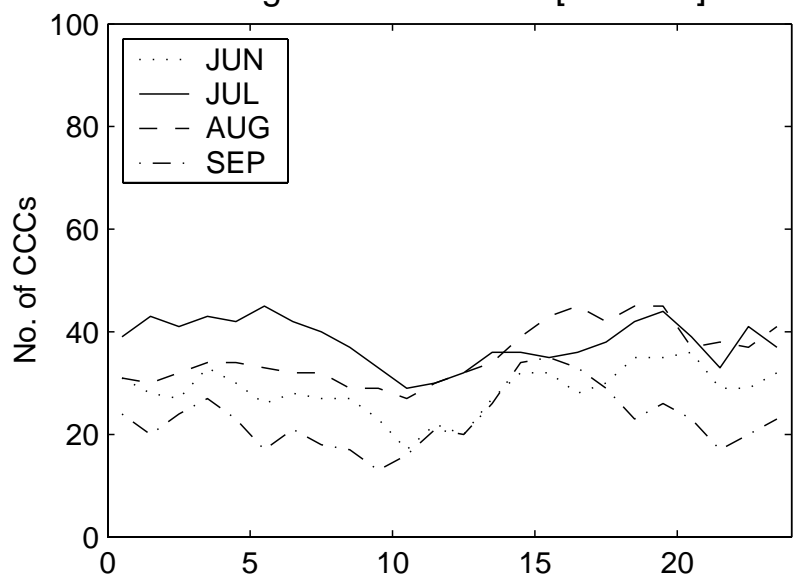

(b) Himalayan Range 2000 [400-4000m]

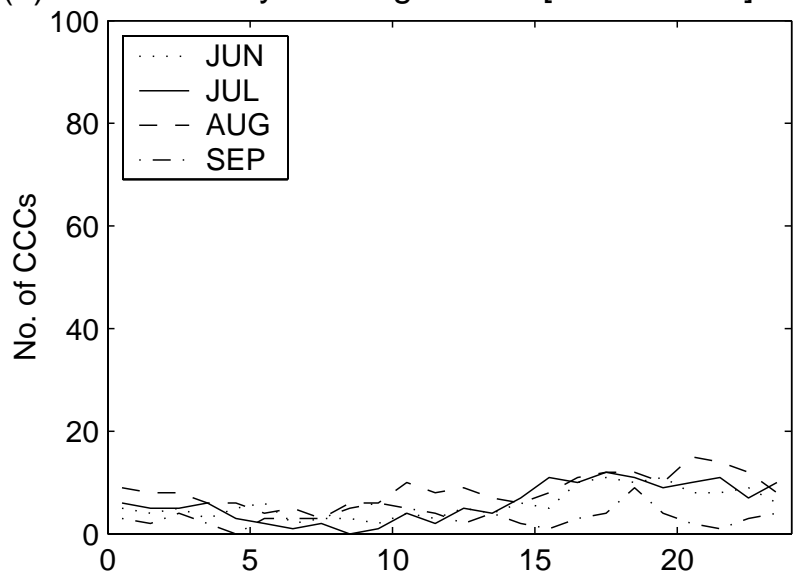

(c)

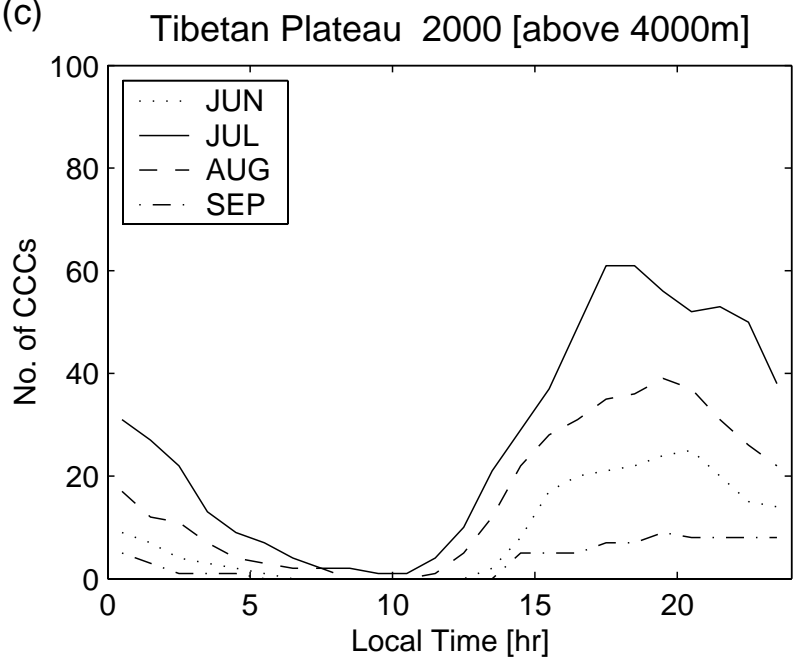

Fig. 6. Diurnal cycle of the number of CCCs from Meteosat5 infrared brightness temperature (BT) images (cold cloud shield for BT <219 K): (a) Gangetic Plains (elevation $<400 \mathrm{~m}$ ); (b) Himalayan range (elevation 400-4000 m); and (c) Tibetan Plateau $(>4000 \mathrm{~m})$. land-atmosphere feedback mechanisms associated with the active and break phases of the monsoon, discussed in Sect. 4. While the characteristic duration of MCCs is on the order of $10-12 \mathrm{~h}$, the characteristic lifetime of CCCs is about $8 \mathrm{~h}$, which contrasts with an average duration of $2 \mathrm{~h}$ for DSCs. These results are similar to those of Laing and Fritsch (1993) for the Indian subcontinent region although we use somewhat different defining criteria as explained above, and our study is centered on a smaller study area and at finer resolution $((\Delta t=1 \mathrm{~h}, \Delta l=10 \mathrm{~km})$ here versus $(\Delta t=3 \mathrm{~h}, \Delta l=30 \mathrm{~km})$ in Laing and Fritsch).

\subsection{Discussion of results from infrared imagery}

Frequency contour plots of CCCs and DSCs displayed in Fig. 5 illustrate the advance and retreat of the monsoon as it propagates away from the Bay of Bengal to the entire region (June, July) and then recedes late in the season (August, September). Typically, the core inner regions of the CWS are about $1 \mathrm{~km}$ deeper than the outer cold shield, and the cloud tops are generally at least $10 \mathrm{~km}$ above mean sea level. The diurnal variation of CCCs and DSCs with elevation was assessed for three different physiographic regions: the Gangetic Plains $(0-400 \mathrm{~m})$, the Himalayan range (400 $4000 \mathrm{~m})$, and the Tibetan Plateau $(>4000 \mathrm{~m})$. The diurnal distribution of the average number of convective cloud clusters during the 2000 monsoon is shown in Figs. 6a-c for each region. Figures $7 \mathrm{a}$ and $\mathrm{b}$ show the diurnal variation of the spatial distribution of the locations where the outbreak of CCCs was first detected. By surveying the spatial organization of convection, one outstanding feature is the dichotomy between the diurnal cycle in Tibetan Plateau and the Gangetic Plains: CCCs and DSCs begin in the Tibetan Plateau in the mid-afternoon into the evening; while they are most active in the midnight and early morning in the Gangetic Plains and along the southern- facing flanks of the Himalayas. This is consistent with Murakami (1983), who examined the phase and amplitude of the diurnal activity of convection over the western Pacific and Southeast Asia using imagery from the Japanese geostationary meteorological satellite imagery. He found that the diurnal convection over the Tibetan Plateau is enhanced in the afternoon and is suppressed in the early morning during the summer monsoon, while on the eastern foothills of the Himalayas heavy convection prevailed in the early morning and was suppressed in the afternoon.

Regions of strong low-level shear and high atmospheric instability develop on the N-NW flanks of monsoon vortices along the Himalayas and against the smaller Aravalli and Maikala mountain ranges in the Madhya Pradesh (Lang and Barros, 2002; Figs. 1 and 4c). Krishnamurti and Kishtawal (2000) examined the diurnal mode of the Asian summer monsoon using data from Meteosat-5 and TRMM. They found that the Tibetan high and the tropical easterly jet are prerequisites of the environment favorable for the movement of mesoscale convective weather systems. The motion of convective cloud clusters westward from the Bay of Bengal 
in the daytime and a reverse motion in the early morning appears to be related to the formation of a low-pressure system in the afternoon over northern India. In our study, the characteristic moving direction of CWSs is associated with the spatial characteristics of this wind pattern. Overall, convective activity is largest in the eastern part of the study area, near the Bay of Bengal, with contrasting scarcity in the western part of domain, especially in the Great Indian Desert on the western side of the Aravalli Range. Furthermore, by tracking the life cycle of MCCs from inception to dissipation, we found that trajectories remained constrained to the Ganges river valley and on the eastern seaboard of the Indian subcontinent, consistent with the path of monsoon depressions originating from the Bay of Bengal during the initial active phases of the monsoon.

The time series of frequency and longitudinal centroid positions of the three types of CWSs, and the Hovmöeller diagram of average hourly cloud density over the region of study, are depicted in Fig. 8 for 1999 and 2000. To define cloud density the hourly values of infrared BT for each longitude were averaged between $20-35^{\circ} \mathrm{N}$. The red arrows mark the dominant directions of airflow during monsoon onset (moist southeasterly winds from the Bay of Bengal). During the demise phase of the monsoon, past mid-August, southerly flow predominates. In the Hovmöeller diagram, note that the easterly propagating trend of increasing cloudiness moving from the Bay of Bengal $\left(90^{\circ} \mathrm{E}\right)$ during the active phases of the monsoon does not generally extend beyond the Aravalli Range in the eastern part of the Madhya Pradesh $\left(75^{\circ} \mathrm{E}\right)$. The influence of orography in defining this east west split pattern in cloudiness will be revisited in Sect. 4. Three distinct types of temporal variability can be identified: 1) the daily cycle; 2) a 3-5 day variability associated with the passage of baroclinic waves; and 3) an underlying low-frequency signal associated with the so-called monsoon breaks with a recurrence of 15-20 days (break periods are marked in Fig. 8 with black arrows). Throughout this manuscript, we will detect and discuss these principal time scales of intra-monsoon variability using various approaches and methodologies.

Although the analysis of Meteosat data provided a good inventory of convective activity in Northern India and the Tibetan Plateau, there is a conspicuous lack of large convective weather systems along the Himalayan range proper (Figs. 7a and 7b). Lang and Barros (2002) pointed out that precipitation in this region mostly was associated with shallow convection embedded in stratiform precipitation systems during onsets, consistent with the characteristically low frequency of lightning flashes. Analysis of TRMM data, surface observations and model simulations (Barros et al., 2000; Barros and Lang, 2003a, b) indicate that the spatial variability of rainfall is consistent with the spatial variability of orography in the frontal ridge-valley region $(5-10 \mathrm{~km})$, and that the high nocturnal rainfall on the Himalayan ridges results from the synergistic interaction of orographic gravity waves and atmospheric instability. The criteria used to detect CWSs according to cloud-top temperature in the IR algorithm ap-
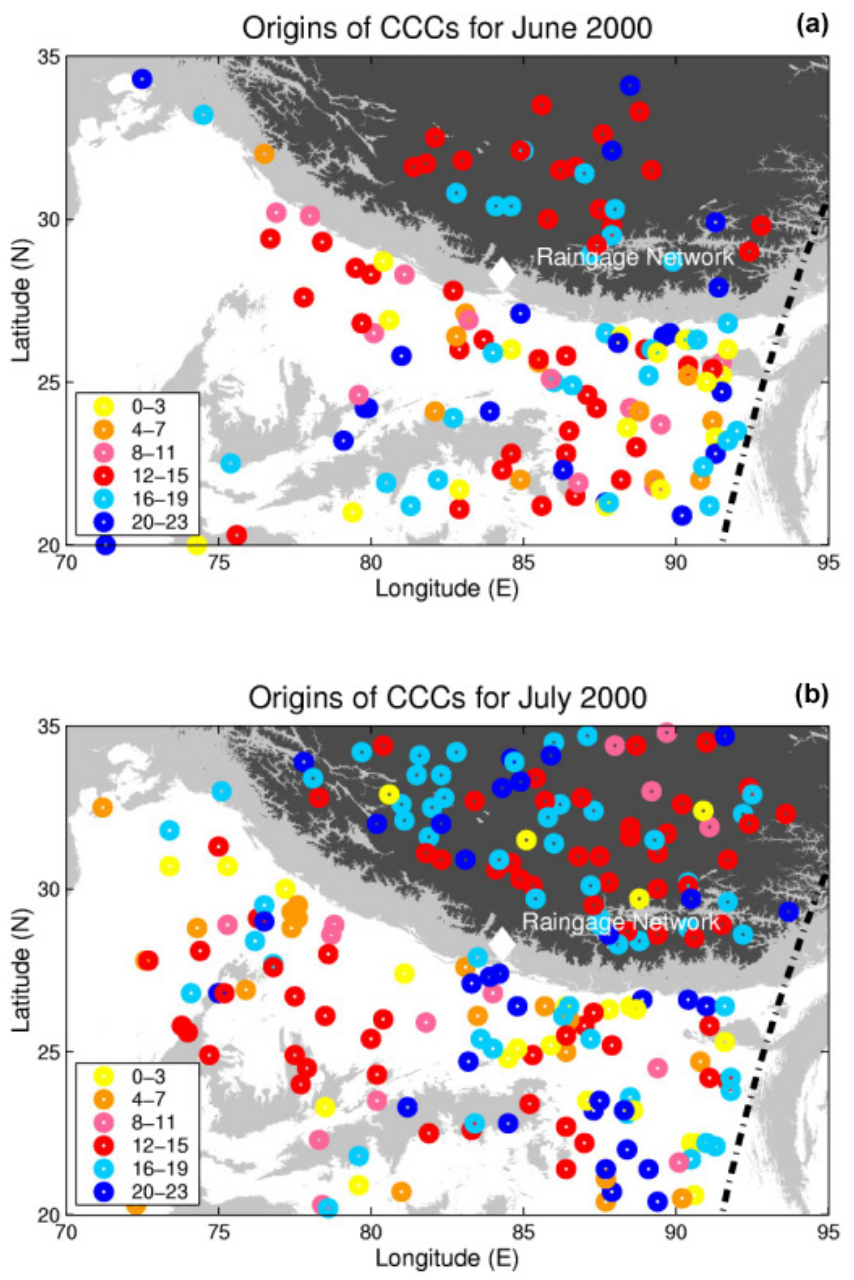

Fig. 7. Diurnal cycle of the spatial distribution of the locations of CCCs' inception in June (a) and July (b) of 2000. The different colors refer to different 4-h periods during the day as per the legend. In the background, the terrain is color-coded for elevation (>2000 m: dark gray; 500-2000 m: light gray; $<500 \mathrm{~m}$ : white. The dotted line indicates the eastern boundary of the Meteosat data image.

pears to eliminate from the analysis all but the most developed (deep and large) convective cells, ignoring medium to low-level convective systems against the Himalayan range, and therefore its utility in mountainous regions is limited. To remedy this problem, we use the algorithm developed by Nesbitt et al. (2000) for high-resolution TRMM data as described next.

\subsection{Analysis using TRMM data}

The Nesbitt et al. (2000) algorithm uses data from two sensors on the TRMM satellite: near-surface PR (Precipitation Radar) reflectivities and TMI (TRMM Microwave Imager) $85.5 \mathrm{GHz}$ polarization-corrected temperatures (PCTs; Spencer et al., 1989) to detect and classify precipitation features $\left(\mathrm{PF}, \geq 75 \mathrm{~km}^{2}\right.$ ) in both continental and oceanic regions. Precipitation features are classified by size and intensity criteria to distinguish between mesoscale convective systems 

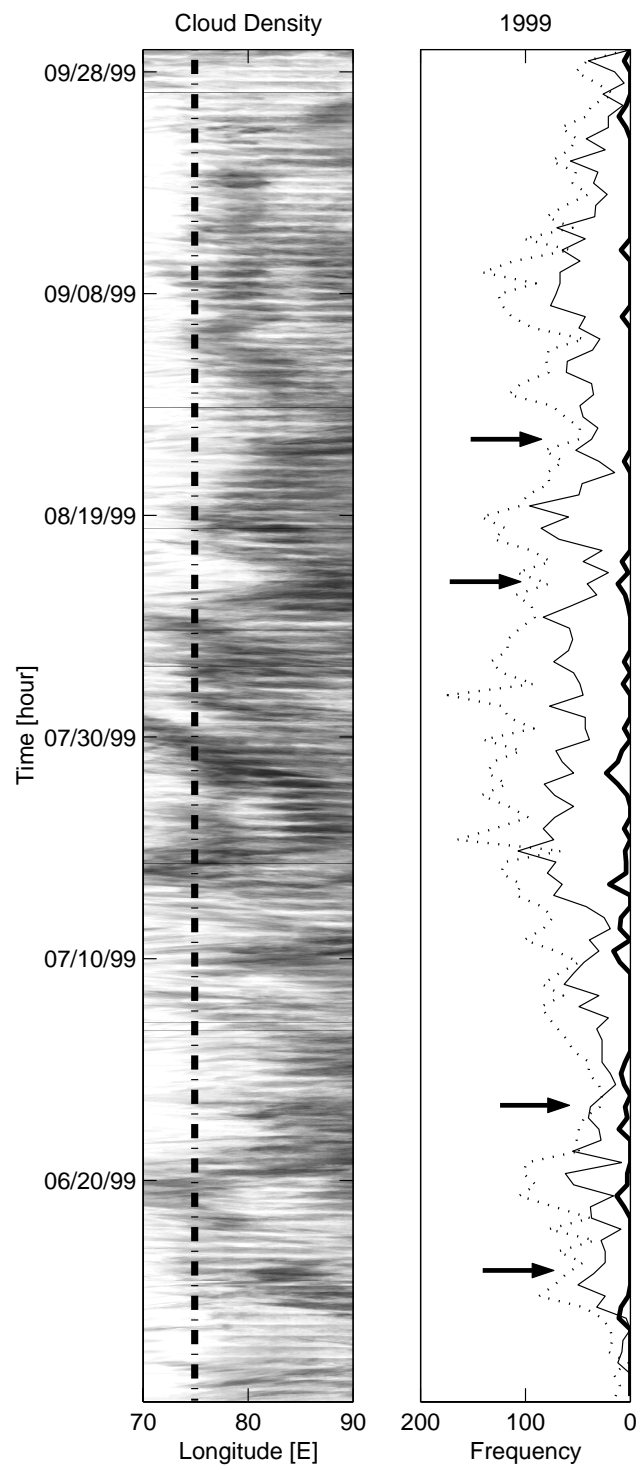

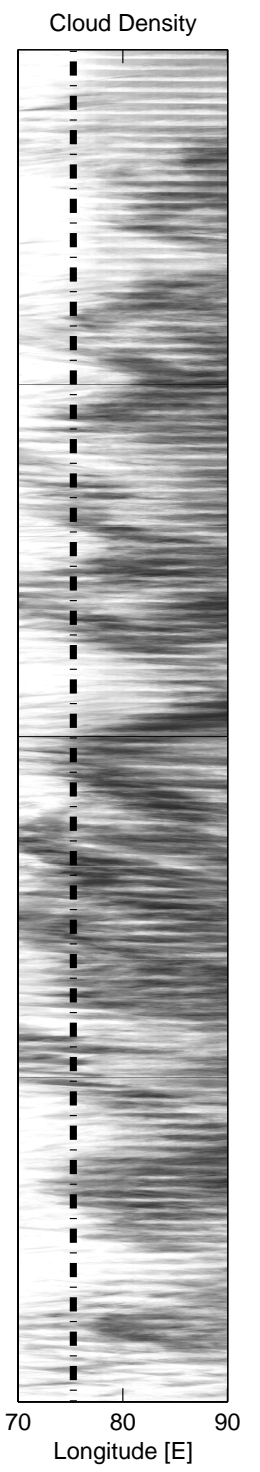

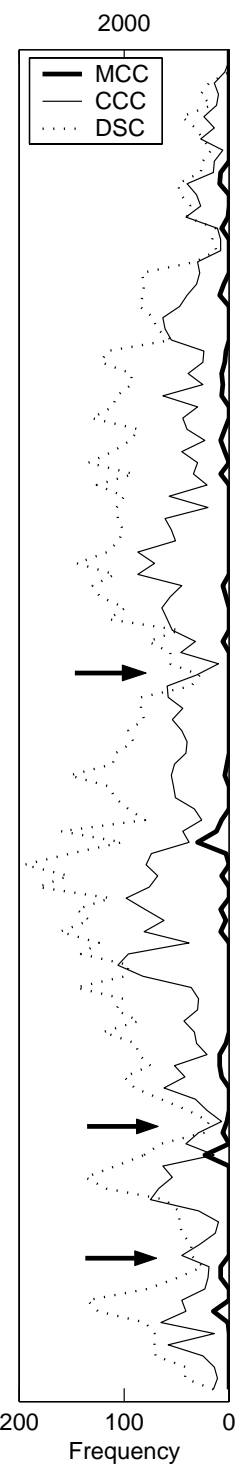

Fig. 8. Hovmeller diagram of cloud density (average infrared britghtness per unit area over the latitudinal band $20-35^{\circ} \mathrm{N}$ ) and CWS occurrences during the 1999 and 2000 monsoon seasons. The red arrows indicate the period of monsoon onset. The black arrows indicate periods of monsoon breaks. The color scale is from clear (no clouds) to black (overcasts, deep convective clouds with very cold tops). The long dot-dashed line marks the approximate average longitude of the AravalliGarhwal axis (see Fig. 1 for details on geographic location). for PCTs below $250 \mathrm{~K}$, and other features for warmer PCTs. Classification criteria were selected to accomplish several goals: 1) best spatial sampling; and 2) differentiation of shallow and deep systems using the ice-scattering signature from the TMI and the low-level PR reflectivities.

Because the TMI and the PR have different scanning strategies, a nearest neighbor interpolation method is employed, using the PR data bin locations as the final, irregular grid. In addition, the algorithm is only employed within the PR data swath. Given the coarser resolution of the TMI, this means that a single TMI bin is allotted to 2-3 different PR bins. Precipitation features (PFs) are systems that have 4+ contiguous data bins with reflectivities $\geq 20 \mathrm{dBZ}$ at the surface, or PCT $\leq 250 \mathrm{~K}$, which allows including both shallow rain and deep anvils. Additionally, PCTs corrupted by snow cover are accounted for by requiring max PR near-surface reflectivity $(Z)$ to be $Z>15 \mathrm{dBZ}$ in a feature with $\mathrm{PCT} \leq 250 \mathrm{~K}$. Three different types of PFs are identified with the algorithm: 1) PF without ice scattering (near-surface PR threshold met but PCT threshold not) - this is essentially warm rain and/or decaying convection (PF-I); 2) PF with ice scattering (PR and/or TMI thresholds met, plus at least one data bin with PCT $\leq 250 \mathrm{~K}$ if only PR threshold met) - these criteria apply to all deep convection short of an MCS (PF-II); and 3) PF with an MCS (based on Mohr and Zipser, 1996; requires that PFs meeting criterion 2 also have 108 contiguous data bins or $\sim 2000 \mathrm{~km}^{2}$ of area with PCT $\leq 250 \mathrm{~K}$, in addition, 10 noncontiguous data bins or $\sim 185 \mathrm{~km}^{2}$ area need PCT $\leq 225 \mathrm{~K}$ ) (PF-III).

Figures 9a and $\mathrm{b}$ show the cumulative occurrences of PF-I and PF-II during the 1999 and 2000 monsoons respectively. Precipitation features with an MCS (PF-III) are absent consistent with the analysis of Meteosat-5 data. TRMM PR overpasses were composited for an entire monsoon season (JJAS) to ensure proper sampling due to the PR's narrow swath $(220 \mathrm{~km})$. The most remarkable feature of these images is the concentration of PF-I on the protruding ridges of the Himalayas, with a characteristic spatial scale of $20-30 \mathrm{~km}$ and 


\section{PF-I 1999}

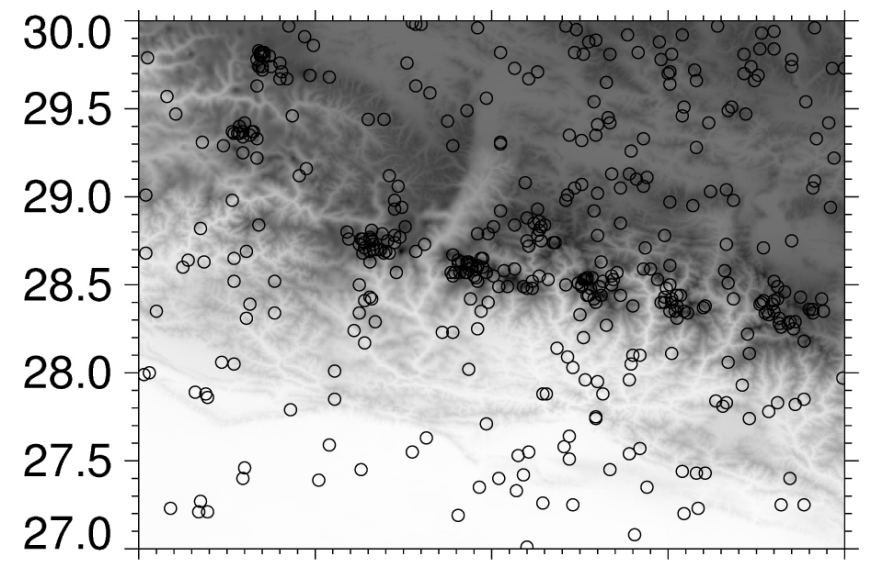

82

83

84

85

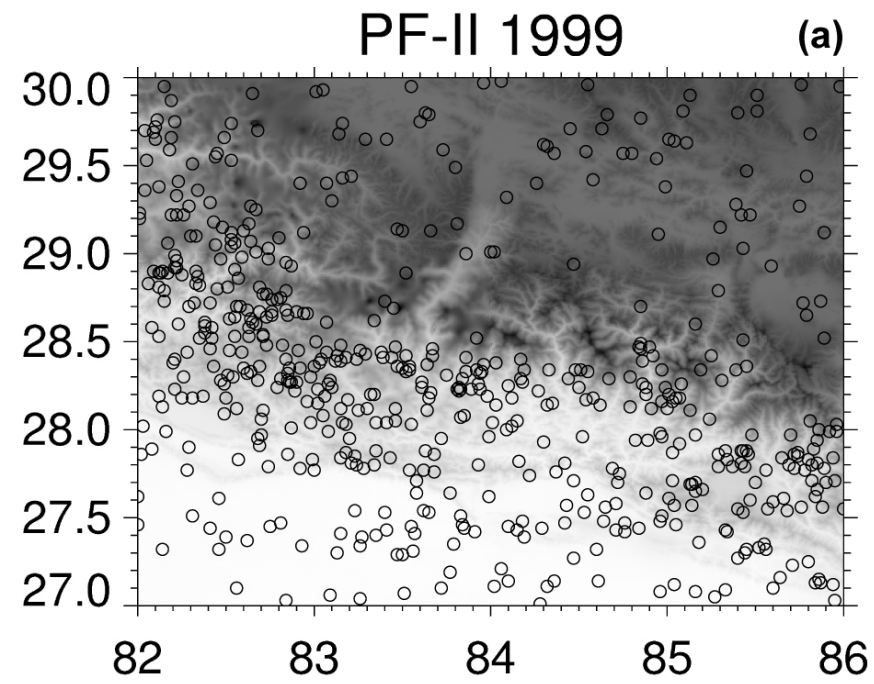

(a)

\subsection{2
2
2 29.5
29.0
28.5
27.5
27.0}

(b)
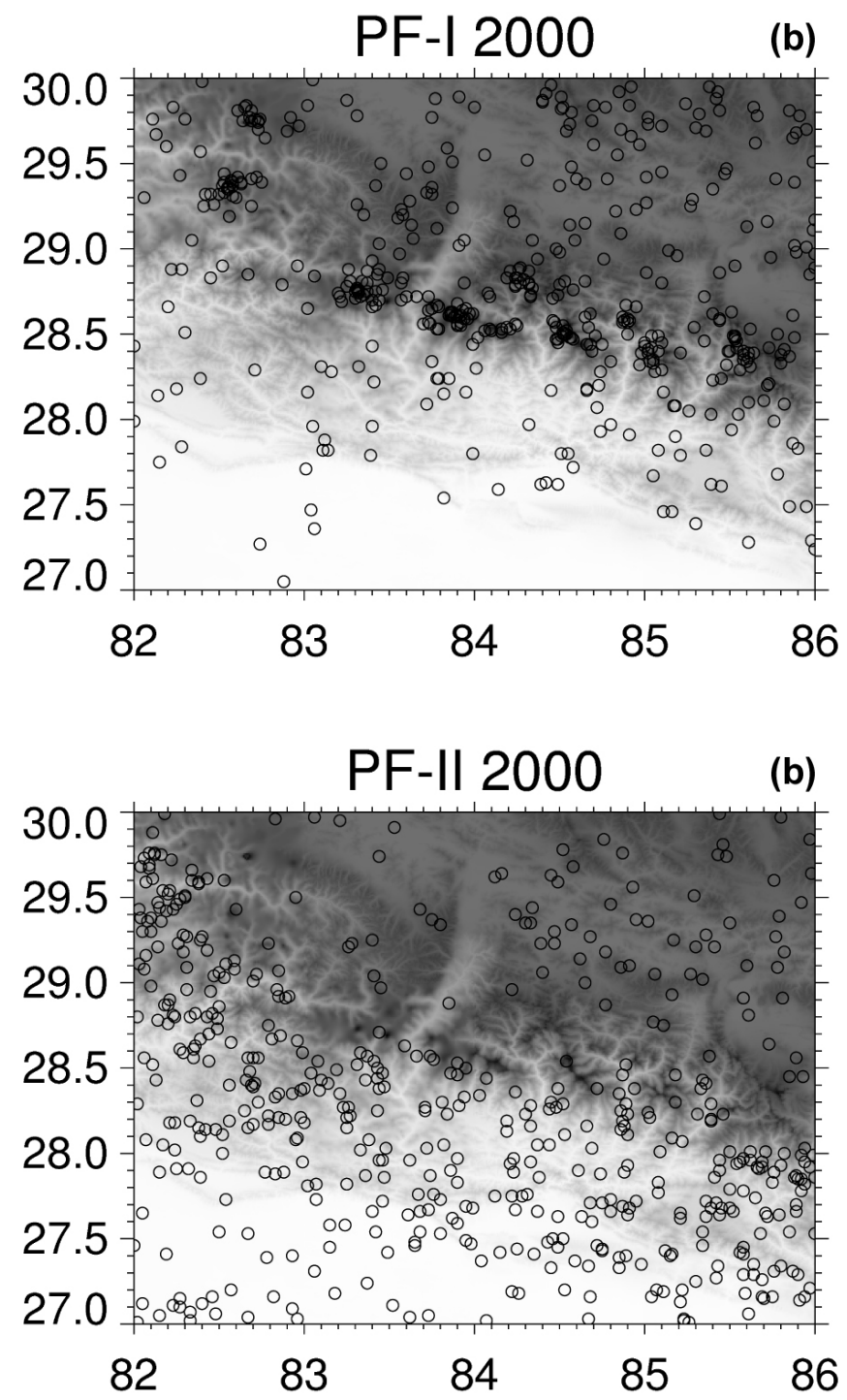

Fig. 9. Monsoon composite (JJAS) of the spatial distribution of precipitation features with and without ice scattering in the region of the hydrometeorological network: (a) during 1999; and (b) during 2000.

strong incidence of these features at nighttime (not shown). In addition, the concentration of PF-II along the foothills is in agreement with the lack of deep CWSs in the IR data analysis. These results are consistent with the spatial patterns of the diurnal cycle of precipitation observations in the region (Barros et al., 2000; Fig. 2), and with patterns from high-resolution numerical simulations discussed earlier (Barros and Lang, 2003b). Furthermore, because the results are systematic across the Himalayan range, they support our conceptual model of the physical mechanisms that determine the spatial variability of clouds and precipitation, specifically post-separation of orographic gravity waves in response to SE monsoon flow modulated by surface heating.

\section{Regional modes of space-time variability}

So far, we investigated the relationship between space-time variability of deep convection and the regional orography. In order to further generalize our analysis of orographic landatmosphere interactions in this region, we now try to identify the relationship between the terrain and dominant modes of variability of cloud fields, and between the latter and relevant circulation indices such as vorticity and divergence fields. For this purpose, we make use of both EOFs (Empirical Orthogonal Functions) and CC (Canonical Correlation) analysis following closely von Storch and Zwiers (1999) as explained in Appendices A and B.

EOF analysis was employed to characterize the dominant synoptic-scale modes of spatial variability of cloudiness and their relationships to landform and orography, and to characterize the temporal variability of dominant spatial modes. The spatial patterns of the first four EOFs (i.e. the eigenvectors of the autocovariance matrix) are shown in Fig. 10a for June 2000, with similar results for all other months and years. The spatial pattern corresponding to the first principal component (EC1; Fig. 10a) is consistent with the split of 

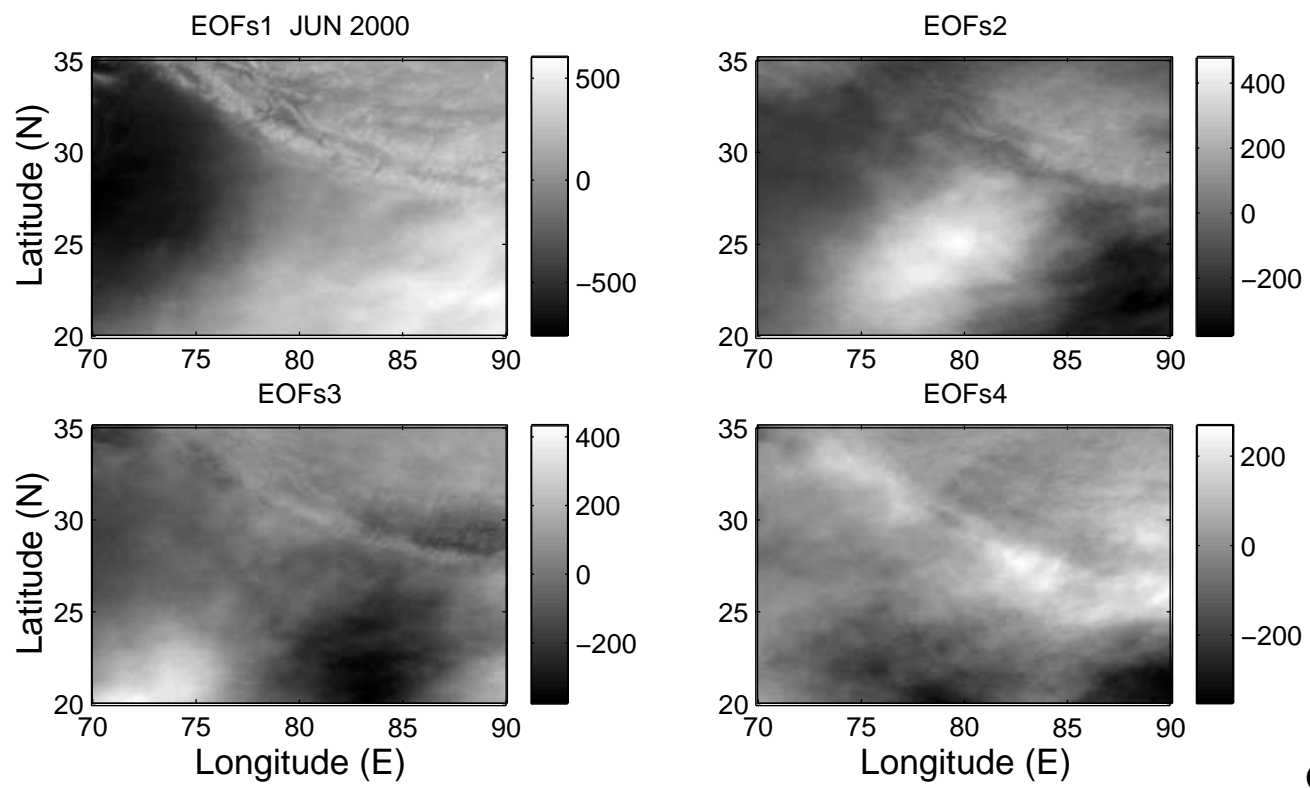

(a)
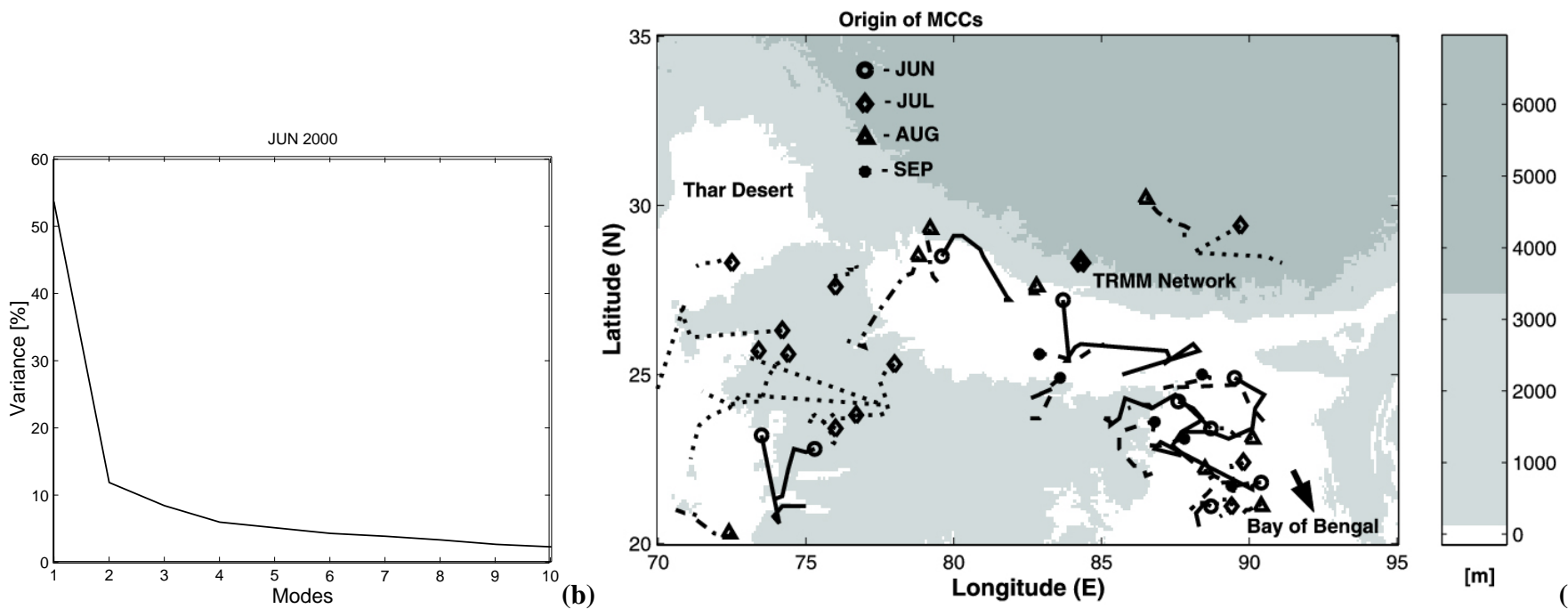

(c)

Fig. 10. (a) Sample fields of the first four EOF (empirical orthogonal function) coefficients (EC) of cloudiness for June 2000; (b) fractional variance explained by the modes of variability represented by the EC mode number; (c) location of inception and trajectories of mesoscale convective systems (MCSs) during 2000. (Dashed line indicate position of the Himalayan range.)

synoptic-scale circulations in the region during the monsoon east and west of the Aravalli range, and the associated gradient of moisture convergence: large in the area under direct influence of the Bay of Bengal (the NICZ), and weak over the Great Indian Desert in the western part of the domain (Murakami et al., 1999; Lang and Barros, 2002; Figs. 4b and 4c). The first principal component (that is, the first mode in Fig. 10b) explains $45 \%$ of the variance. The second principal component explains $12 \%$ of the overall variance, and the corresponding spatial pattern (EC2) exhibits a strong SW-NE axis in alignment with the eastern boundary of convective activity along the Aravalli Range, including the low elevation $(\sim 500 \mathrm{~m})$ topographic divide that separates the Ganges from the Sutlej River Valley, up to the Garhwal Himalayas in northern India (Fig. 1; Fig. 10c). The temporal variability of the two first principal components was examined using wavelet analysis (please see Appendix $\mathrm{C}$ for details on the methodology). EC1 coefficients show a strong daily cycle, as well as a 4-day time scale consistent with the passage of baroclinic disturbances (Fig. 11a). While EC2 does not exhibit a diurnal cycle, it does show a strong nonstationary oscillation with a time-scale of 10-15 days consistent with the active and break phases of the monsoon in June (Fig. 11b). Later in the monsoon, the time-scale of this oscillation increases up to 20-25 days (not shown). 

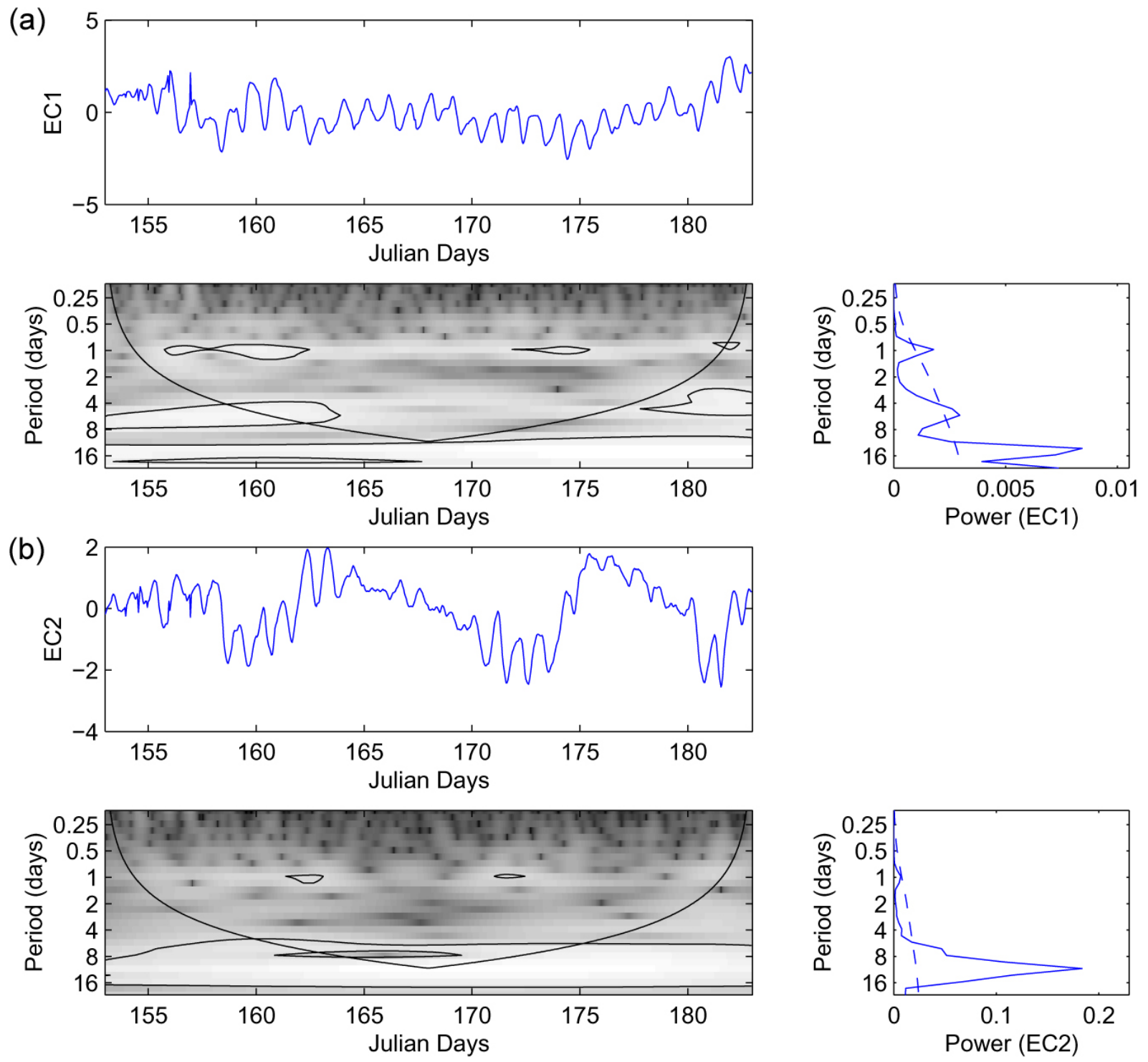

Fig. 11. Wavelet analysis of the first (a) and second (b) EOFs for June 2000 from Fig. 10a. The wavelet power spectrum shows the contribution of the different time-scales (periods) to the variance as a function of time. The global wavelet power spectrum (on the righthand side) is the sum of the contributions of the wavelet power spectrum at each time-scale during the entire period for which data are available. (Light gray tones inside back contour lines indicate contribution at the $95 \%$ confidence level.)

Canonical correlation (CC) analysis was used to characterize the joint variability of cloudiness and indices of atmospheric circulation including divergence and vorticity fields. Vorticity and divergence were calculated from ECMWF objective analyses, which were available at $2.5 \times 2.5^{\circ}$ horizontal resolution and 12-h temporal resolution, extracted from the NCAR Mass Storage System. Because of the large difference in spatial resolution between the circulation fields $(\sim 250 \mathrm{~km})$ and the IR imagery $(\sim 10 \mathrm{~km})$, the latter was first aggregated to the resolution of the former before CC analysis was conducted. Figure 12 shows the first two leading canonical correlation patterns of brightness temperature (BT) and vorticity at $700 \mathrm{hPa}$ for June 2000. The first pair of leading patterns is similar to the first principal component of each field. The second pair of leading patterns is also similar to the second principal component of each field (see Fig. 10a for the principal components of the cloudiness fields). Although this is not a necessary result from CC analysis (the objective of $\mathrm{CC}$ analysis is to find the patterns that explain the maximum cross-covariance between two fields), it strengthens our interpretation of the dynamical basis of the EOF patterns identified previously. The first pair, which explains more than $80 \%$ of the total crosscovariance (not shown), shows cyclonic activity on the SE quadrant in the area of influence of the Bay of Bengal and an anticyclonic center in the Great Indian Desert consistent with the synoptic circulation in the region as discussed earlier. The second pattern shows landform controls on the organization of $700 \mathrm{hPa}$ vorticity fields, 

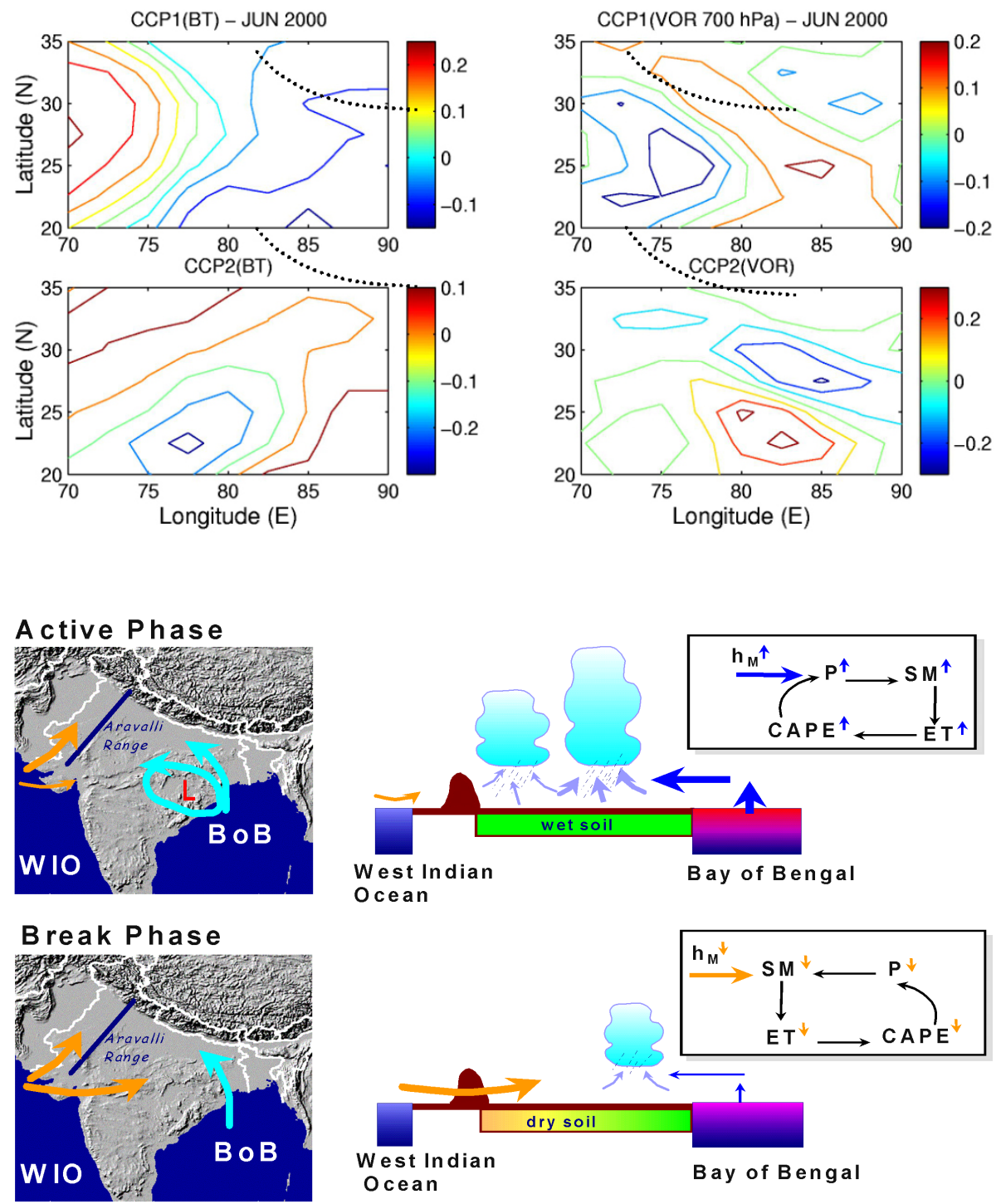

Fig. 12. Canonical Correlation (CC) analysis of the joint variation of cloudiness and $700 \mathrm{hPa}$ vorticity fields: first (CCP1) and second (CCP2) patterns.
Fig. 13. Graphical depiction of landocean atmosphere interactions during active (top) and break (bottom) phases of the monsoon. Blue upward arrows indicate positive feedback. Orange downward arrows indicate negative feedback. (hM - moist energy flux; P - precipitation; SM - soil moisture; ET - evapotranspiration; CAPE Convective Available Potential Energy; WIO - Western Indian Ocean; BoB Bay of Bengal). consistent with the role of land convection, and the Northern India Convergence Zone (NICZ) on the valley of the Ganges, with the Himalayas to the north, the Maikala Range to the south, and the Aravalli-Garhwal axis to the west (Fig. 1). This is also consistent with the temporal variability of the canonical covariance coordinates (not shown), which exhibit the 10-15 day cycle period previously identified in the EOF analysis.

Likewise, analysis of the first two leading patterns of the cross-covariance matrix of brightness temperature and 700 -hPa divergence shows that the fraction of the total crosscovariance explained by the first pattern is roughly $90 \%$, with a subsidence region in the Great Indian Desert consistent with the anticyclonic center in Figs. $4 \mathrm{~b}$ and 12. This region of subsidence can be explained by the monsoon-desert mechanism proposed by Rodwell and Hoskins (1996) associated with the westward propagation of a Rossby wave generated in the eastern portion of the continent by the monsoon latent heating. This mechanism was used by Chou et al. (2001) to explain east-west asymmetries in rainfall distribution (and convective activity) for an idealized simulation of the monsoon, which also were noted earlier by Xie and Saiki (1999) and Dirmeyer (1998). The second leading pattern indicates a region of convergence between the Aravalli and the Maikala Ranges consistent with the position of the eastern boundary of the NICZ, where deep convection occurs. This analysis suggests an east-west convergence-subsidence dipole over the northern Indian subcontinent, the geographic boundary of which is defined by the axis that connects the Aravalli range to the Garhwal Mountains (Fig. 1). Although orography is not the necessary cause of this east-west asymmetry as explained by the Rodwell-Hoskins mechanism, our data analysis shows that landform mimics its spatial dynamics.

Together, the results of the EOF and $\mathrm{CC}$ analysis provide support to an explanation of ocean-land-atmosphere feedbacks and the active and break phases of the monsoon that integrates recent findings by Chou et al. (2001), Vecchi and Harrison (2002), and Lang and Barros (2002) illustrated 


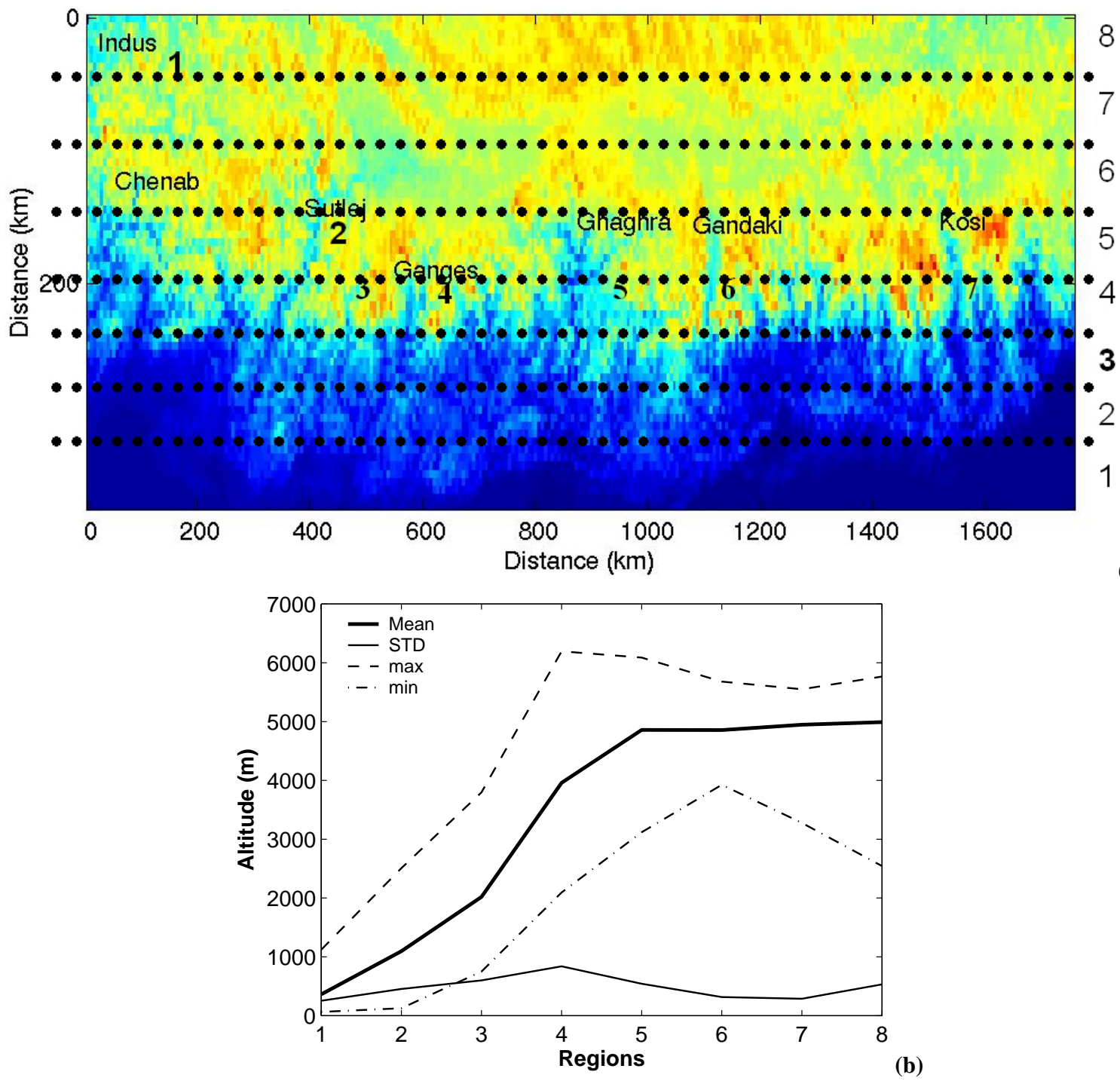

Fig. 14. (a) Orthorectified and rotated DEM of the region of study. (Regions $1-8$ correspond to the marked elevation bands. The river valleys previously identified in Fig. 1 are also marked). (b) statistical description of the elevation distribution within each region.

in Fig. 13. As suggested by LB and VH, warming periods in the Bay of Bengal play an important role in the onset and active phases of the monsoon through southeasterly monsoon depressions that originate in the BoB and propagate over northern India, and by maintaining sustained convergence of moist available energy to the NICZ and the Himalayas east of the Aravalli range. Drier air originating from the Arabian Sea in the Western Indian Ocean (WIO) is constrained to the west. The active phase of the monsoon is maintained via a positive feedback mechanism of land-atmosphere interactions. Increased rainfall in the east leads to an increase in soil moisture conditions, increase in surface latent heating due to increase in evapotranspiration, increase in CAPE (Convective Available Potential Energy), intensification of convective activity and increased rainfall over the region (Fig. 13, top). Cooling periods in the BoB lead to a decrease in moisture convergence over the conti- nent, weakening of the regional circulation east of the Aravalli range, thus allowing ventilation of the central portion of the Madhya Pradesh through penetration of westerly dry air and decrease of available soil moisture. Accordingly, the break phase of the monsoon is maintained by a negative feedback mechanism of land-atmosphere interactions (Fig. 13, bottom). Increased ventilation by dry westerly flow leads to a decrease of soil moisture that is not replenished, which leads to a decrease in evapotranspiration and surface latent heating, lower CAPE, weakening of convective activity and less rainfall. These pulses of the monsoon can be monitored by tracking the space-time evolution of cloud fields, thus providing support to a causal relationship between the spacetime modes of variability of cloudiness and the underlying dynamics, which therefore strengthens our assertion that we can use the cloudiness as a dynamic proxy of the space-time variability of precipitation in the region. 

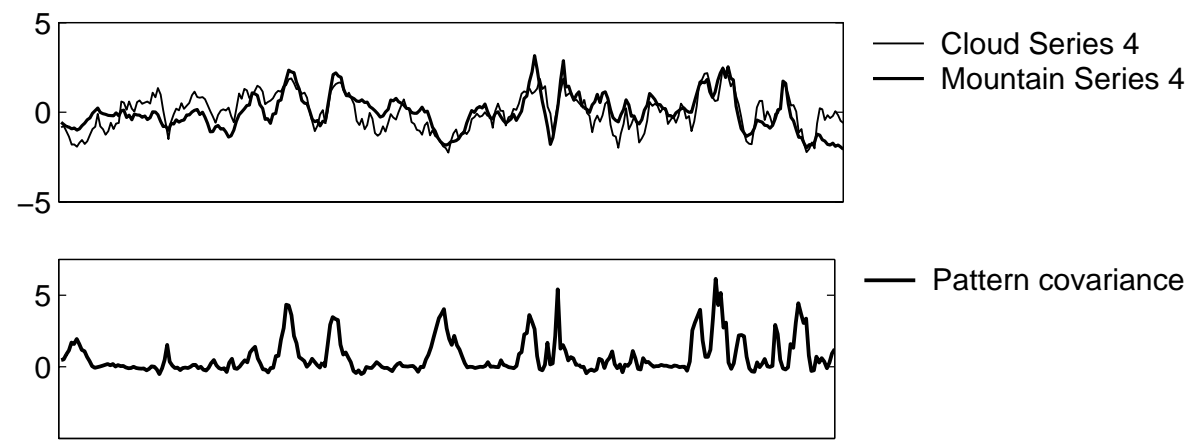

\section{— Pattern covariance}

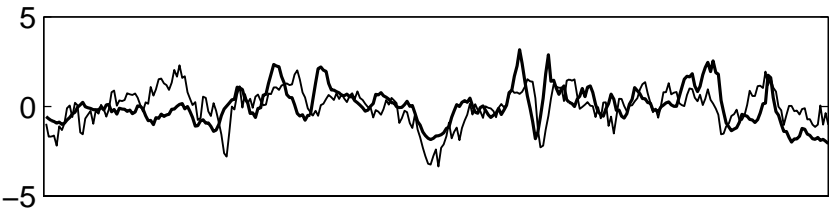

Cloud Series 4

Mountain Series 5

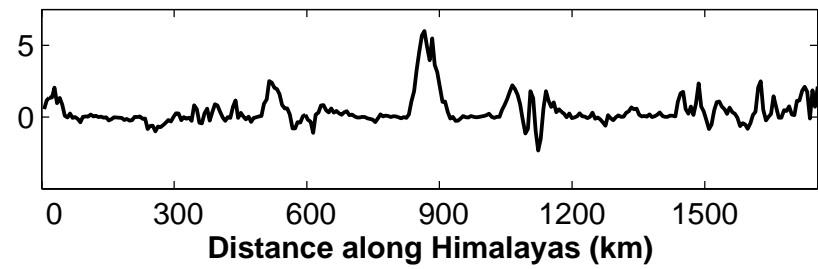

- Pattern covariance

Fig. 15. Pattern Covariance (PC) analysis between the zonal anomalies of the terrain (regions 4 and 5) and the time-averaged spatial anomalies of cloudiness (region 4) for the 1999 monsoon season.
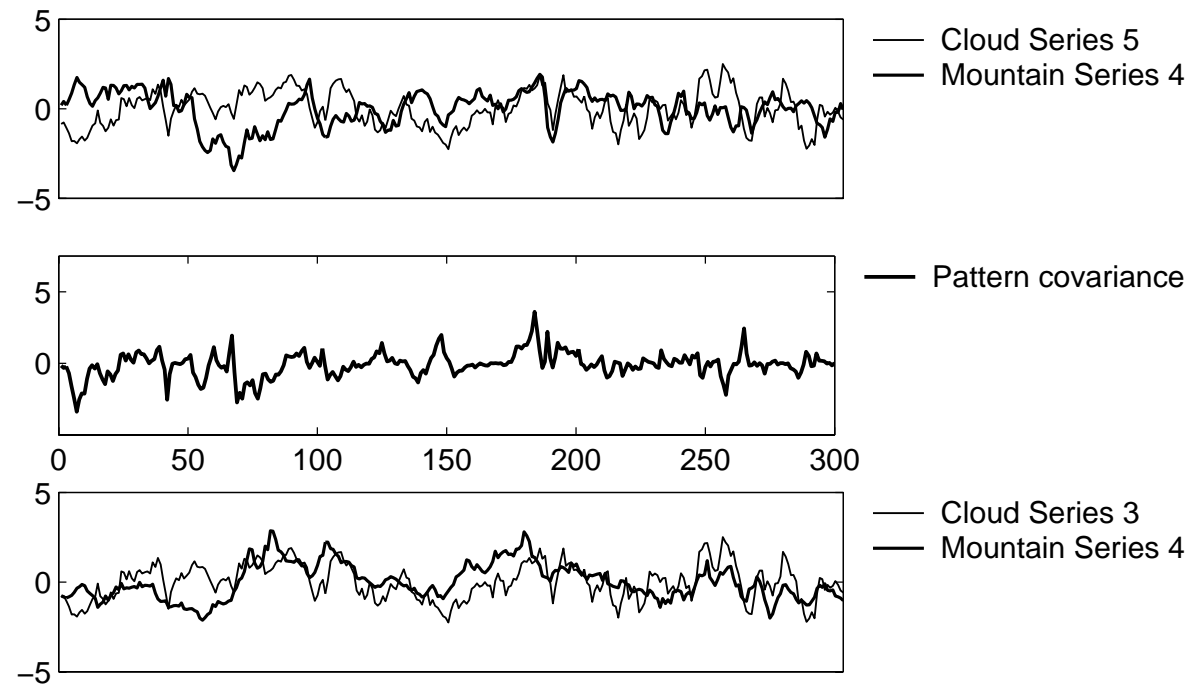

Cloud Series 3

— Mountain Series 4

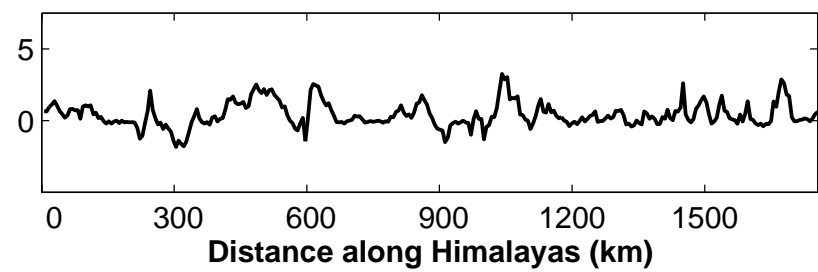

- Pattern covariance

Fig. 16. Same as Fig. 15 for zonal anomalies of the terrain (region 4) and the time-averaged spatial anomalies of cloudiness during the 2000 monsoon season in region 5 and region 3. 


\section{Orography and space-time variability in the Himalayan range}

We now focus on investigating direct linkages between the Himalayan topography and the space-time variability of cloudiness as a function of elevation. The same hourly infrared imagery from Meteosat-5 during monsoon months (June through September) for 1999, 2000 and 2001 described in Sect. 3.1, was analyzed here. Resolution ranged $5-10 \mathrm{~km}$ during the three-year period for the area of study, a $325 \times 1800 \mathrm{~km}$ band along the Himalayan slopes within $20-35^{\circ} \mathrm{N}$ latitude and $70-90^{\circ} \mathrm{E}$ including the Gangetic Plains and the southernmost portion of the Tibetan Plateau.

Because satellite images taken from a geostationary orbit show the curvature of the Earth, the Meteosat-5 images were orthorectified to correct for this bias. In addition, amplitude thresholding was used to eliminate the contribution of snow-covered cold mountaintops that are not also covered by clouds (Rossow, 1989). The Meteosat-5 infrared images consist of spatial fields of brightness (BT) ranging from 0 to 255 (256 levels or shades). In choosing the threshold value (95), cloudy areas could be distinguished by a different textural appearance than the mountaintops, as well as by virtue of the fact that the clouds move while the mountaintops are stationary. To capture the ridge-valley geometry along the southernfacing slopes of the Himalayas, the region of study was then divided into eight equal-area regions or bands at different altitudes separating the foothills, slopes, peaks and plateau. These bands are on the order of $1800 \mathrm{~km}$ long and $40 \mathrm{~km}$ wide. From a bird's-eye view, the Himalayan range is angled to the southeast by $26^{\circ}$ from the horizontal, and curved in the shape of a parabola. To isolate orographically induced spatial variability from that associated with the large-scale layout of the mountains, the data (both terrain and BT fields) were further transformed to match altitude bands following the natural contours of the Himalayas rather than in terms of latitude and longitude lines. Data series were derived from the orthorectified and threshold infrared images to represent the mountains in space and the clouds in space and time. For this purpose, the Digital Elevation Model (DEM) was first rotated by $26^{\circ}$ counterclockwise so that the large valleys in the center of the Himalayan range exhibited approximately north-south orientation in the new coordinate system. Next, a second-degree polynomial curve was applied to the $4000 \mathrm{~m}-$ altitude contour of the Himalayan range in the rotated coordinate system. Finally, the rotated DEM was shifted by the polynomial to straighten the curved axis of the Himalayan range (Fig. 14a). Within each band, the altitude was averaged from top to bottom to create eight data series that have high values at ridges and low values in valleys, from the foothills through the Middle to the Upper Himalayas. The data series thus created represent the level of cloudiness present in each of the regions. Because of our interest in investigating the linkages between orographic gravity waves, cloudiness and rainfall accumulations, we will focus our discussion on altitude bands 3, 4 and 5 (see Fig. 14b for statistics). The same transformation was applied to each Meteosat- 5 infrared

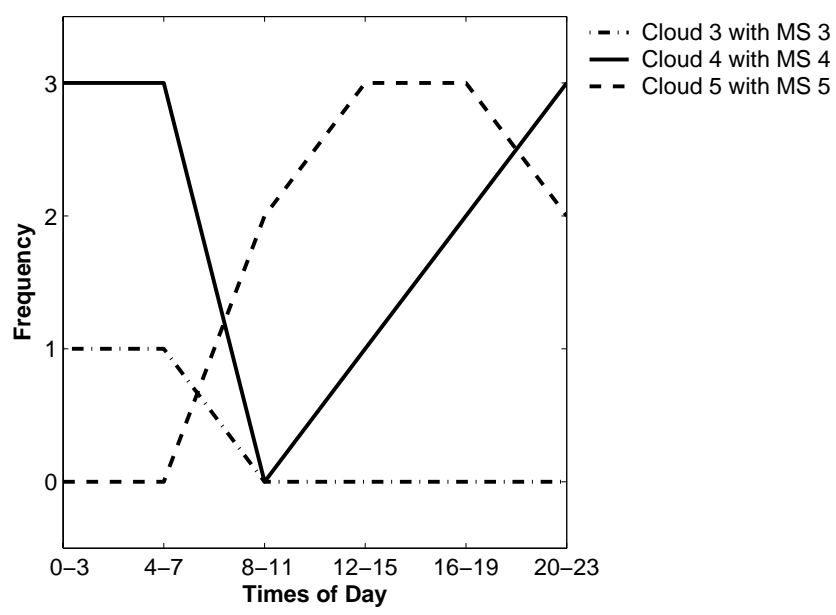

Fig. 17. Diurnal distribution of instances of high pattern covariance values between cloud and terrain anomalies during the 2000 monsoon.

image. For temporal analysis of the cloudiness patterns, we create one-dimensional time series estimating a single hourly average cloudiness in each altitude band.

\subsection{Pattern covariance analysis}

The association between landform and cloudiness was evaluated by calculating the Pattern Covariance Functions (PCFs) of the terrain and the spatial series of temporal averages of normalized cloudiness for each of the 8 altitude bands. The pattern covariance function is defined here as the product of the zonally collocated anomalies of elevation and cloudiness for each band. This concept is similar to the concept of pattern correlation to determine whether two series deviate from the mean in the same or opposite directions. Anomalies of the same sign tend to reinforce each other and result in high positive values, while anomalies of different sign result in negative covariance values (Wilks, 1995). Generally, cloudiness in altitude regions 3-5 exhibits high values of pattern covariance with the corresponding elevation bands, and with adjacent bands.

Figure 15 shows the pattern covariance functions of cloudiness in band 4 and terrain in bands 4 and 5 in 1999, with remarkable similarity of the PCFs in 2000 and 2001 (not shown). Note that despite large differences in landform between bands 4 and 5, we find that the highest positive values of the PCFs in both cases coincide with the spatial location of the valleys of major rivers (marked in Figs. 1 and 14a), which appear to affect spatial variability differently for each region. Three valleys dominate orographic land-atmosphere interactions as described by cloudiness: the Ganges (4), the Ghaghra (5), and the Khali Gandaki (6). The distance between wide river valleys with a strong signature on the mountain anomalies series ranges from 70 to $150 \mathrm{~km}$, although variability at smaller scales also is present. Figure 16 top and bottom panel pairs show the pattern covariance functions between two examples of cloud series ( 5 and 

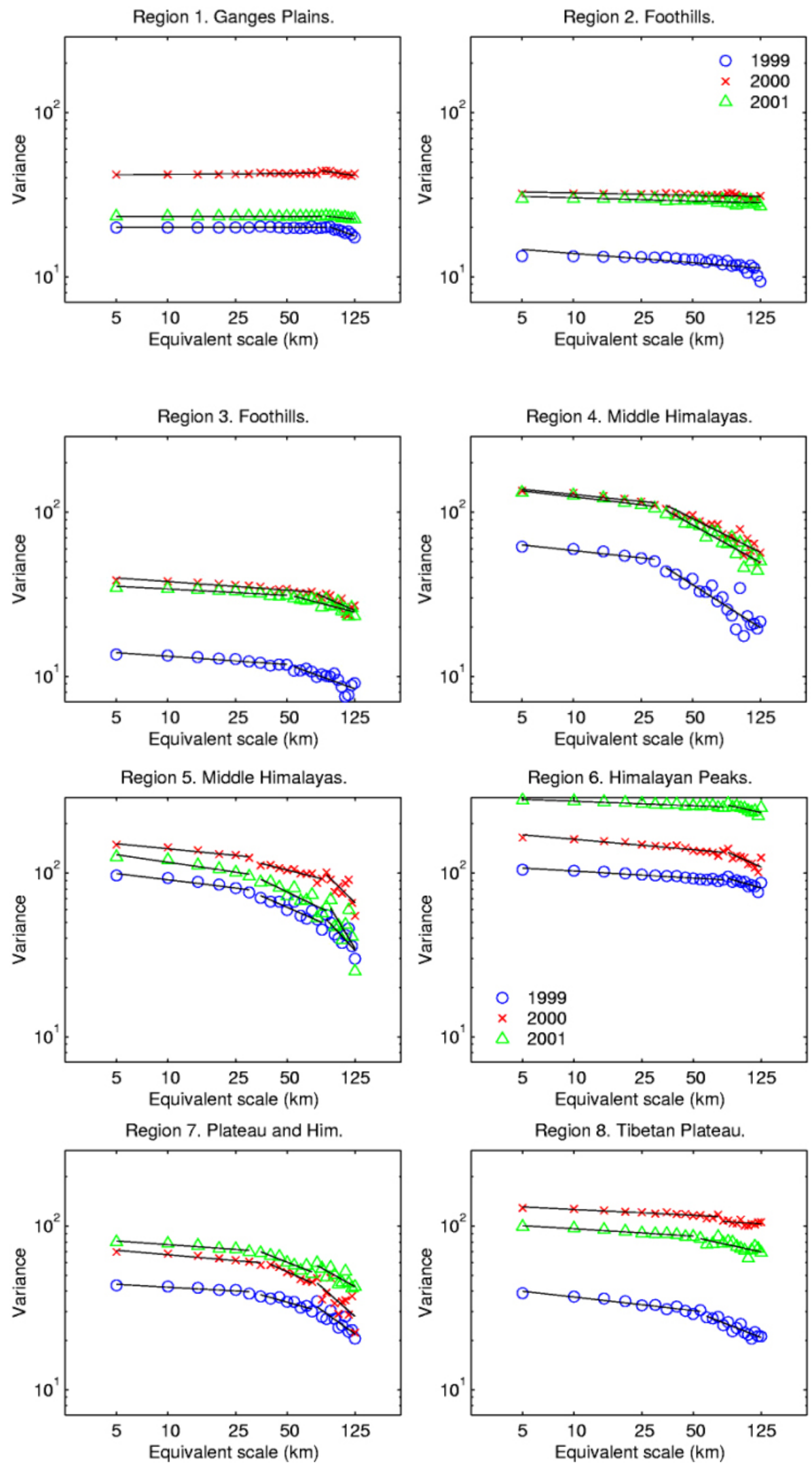

Fig. 18. Scaling analysis of the temporal averages of the cloudiness anomalies for regions 1-8 for 1999, 2000, and 2001. Note year-to-year consistency in the slopes for each region and scaling regime. 
3, respectively) and terrain for elevation band 4. In this case, the PCF values are significantly lower, and mostly negative, except for the large river valleys, which extend over three or more bands, and where coherence among cloud patterns at all elevations is observed. This result is expected as the spatial arrangement of the topography is very complex, altitudinal gradients are very strong, and thus the longitudinal (N-S) coordinates of the valleys change significantly from one band to another, causing spatial mismatch and low PCF values. Nevertheless, the covariances are higher for the interaction between lower altitude bands ( 3 and 4 ) than for the higher altitudes (5 and 4), reflecting the fact that band 5 includes a large portion of the rainshadow regions of the Himalayas, and thus represents a different precipitation regime.

To establish the connections between the terrain and the cloudiness, it is now important to investigate whether the temporal variability in these features is consistent with observations and modeling results that point to the presence of a strong diurnal cycle, with a nocturnal rainfall peak on protruding ridges and an afternoon peak resulting from surface heating effects (Barros et al., 2000; Lang and Barros, 2002; Barros and Lang, 2003a). Figure 17 shows the daily cycle of cloud intensity for elevation bands 3,4 and 5 . In region 5 we see high covariance values at 12:00-19:00 LST, the afternoon and evening. The high cloudiness at ridges at this time of day is most likely due to afternoon convection enhanced by surface heating. In region 4 , covariance and thus cloudiness at ridges are highest during the night (20:00-7:00 LST), centered at 0:00-3:00 LST. We see a less consistent pattern of high covariances between the clouds and the mountain series in region 3, although convection tends to occur in line with ridges in the early morning (4:00 and 7:00 LST) as previously noted for the observations in Fig. 3. Overall, the analysis of the diurnal cycle for the three years of record does confirm rainfall observations as well as radiosonde-based estimates of precipitable water and indices of convective activity (Barros and Lang, 2003b).

To explore further the patterns of temporal variability in the cloud series, wavelet analysis was conducted to identify relevant time scales. Specifically, the Morlet wavelet was used here as proposed by Torrence and Compo (1998), whereby the wavelet time scale can be interpreted conceptually in a manner similar to the Fourier period. Further details are provided in Appendix C. An examination of the wavelet modulus for the time series (not shown) confirms the high degree of intraseasonal variability of cloudiness on the Himalayan range during the monsoon, consistent with our conclusions in Sect. 4. Despite strong interannual variability (Webster et al., 1998), we find that the intra-seasonal variability remains highly consistent from year to year and from region to region. At low elevations (regions 1 and 2), we find that time scales on the order of the 4-5 and 8-10 days dominate the variability in the first half of the monsoon, while longer time scales (15-20 days) prevail in the second half of the monsoon. Two time scales (5-10 and 25-30 days) are dominant in regions 3 and 4 throughout the monsoon. The diurnal cycle gains importance as we move up the moun- tains through regions 3 and 4 , but only becomes statistically significant in regions 5, 6, 7 and 8 . These include large portions of the Tibetan Plateau, where the 5-10 and 25-30 day time-scales remain dominant. We expected from visual analysis of the individual wavelet moduli that the periodicities would show more consistency within a year than within a region across years. To assess whether patterns in the temporal variability of cloudiness exist across regions, we multiplied together the wavelet moduli to compute a cross-wavelet modulus for all regions of a given year. Indeed, we found that the sums of explained variance among regions for any given year are much higher than from year-to-year (not shown).

\subsection{Scaling analysis}

Scaling analysis is used to determine the scaling behavior of a field, whether that is single- or multi-scaling. If multi-scaling, we seek to understand where the scale breaks and what are the dominant spatial scales (Feijt and Jonker, 2000). These values can be used to assess a field's dependence on other spatial variables, or on the observation scale (Veneziano and Iacobellis, 1999). Knowing the scaling behavior of a field provides physical insight into its dynamical behavior, and can be used in downscaling algorithms (Tessier et al., 1993; Kim and Barros, 2002a, 2002b). In this work, we examine the scaling behavior of cloud fields at different altitudes over the Himalayas and attempt to further characterize orographic land-atmosphere interactions and their impact on precipitation processes. A brief overview of empirical scaling concepts is provided in Appendix D.

Variograms of all cloud data series for 1999, 2000 and 2001 are presented in Fig. 18 for regions 1-8, respectively. To identify the location of scale breaks, we computed the Hurst exponents $(\mathrm{H})$ for all possible break points using a best-fit line with the lowest least-squares error. Break points were finally selected at spatial scales where adjacent slopes as measured by the Hurst coefficient (Appendix D) differ by at least 0.1 . Although this value may be considered somewhat arbitrary, we find that it allows for unequivocal separation of scaling regimes in this work. Analysis for spatial scales above $125 \mathrm{~km}$ was not conducted out of concern for reliability of our estimates using fewer than 15 points. The scaling breaks occur at scales ranging between $60-80 \mathrm{~km}$ in elevations bands 3,6 and 8 with larger Hurst exponents for the larger spatial-scales. In regions 4 , 5 and 7 , a third scaling break can be identified at $30 \mathrm{~km}$ with average Hurst coefficients below 0.1 (and fractal dimension $D>1.9$ ) for the smaller scales. The use of a less stringent criterion for slope separation would have allowed for the identification of a scaling break at roughly $80 \mathrm{~km}$ as in regions 5 and 6 . Generally, inspection of the variograms in Fig. 18 suggests three different scaling regimes of orographic land-atmosphere interactions: 1) a synoptic-scale regime $(\geq 70-80 \mathrm{~km}) ; 2)$ an orographic meso $-\beta$ regime $(30-70 \mathrm{~km})$ associated with the succession of wide valleys and bulky terrain features; and 3) an orographic meso- $\alpha$ regime $(\leq 30 \mathrm{~km})$ associated with the complex succession of 
protruding south-facing ridges and narrow valleys that characterize the Himalayan foothills between altitudes of 3000 and $5000 \mathrm{~m}$ elevations.

Focusing on the southern-facing slopes, the scaling behavior in regions 3-8 can be directly linked to characteristic wavelengths of the topography in these regions (Fig. 14a): the complex sequence of narrow valleys and ridges for scales between 5 and $30 \mathrm{~km}$ in regions 4 and 5 , and the impact of the wider valleys in regions 5 and 6 . In regions 1 and 2, the cloud series show single-scaling (self-similar) behavior with low Hurst exponents. In 1999, monsoon depressions originating from the Bay of Bengal tended to exhibit a $\mathrm{N}-$ NW path significantly closer to the mountains than in 2000 and 2001 (Lang and Barros, 2002), which may explain the multiscaling behavior in region 1 . On average, the Hurst exponents for scales below $30 \mathrm{~km}$ are around $0.05(D=1.95)$, $0.17(D=1.83)$ for scales between 30 and $80 \mathrm{~km}$, and 0.44 $(D=1.56)$ for scales above $80 \mathrm{~km}$. This shows a decrease in spatial organization (and impact of organized orographic forcing) with increasing spatial scale as large-scale dynamics take over (Fabry et al., 1996). The character of interannual variability implied by the multifractal behavior of the cloud fields for the three years require additional comment. Consider the differences between the variograms for 1999, 2000 and 2001 in all regions, but especially in regions 2, 3 and 4, which we attribute to differences in frequency and path of BoB depressions in these years. In 1999, the monsoon onset as well major storm events in the Central Himalayas were associated with strong depressions with SE trajectories that eventually lead to collision or close encounter with the mountains (Lang and Barros, 2002). By contrast, in 2000 and 2001, the frequency of such events was much reduced and the trajectories of major storm systems tended to follow a direction parallel and removed away from the mountains.

\section{Summary and discussion}

Convective weather systems identified by Meteosat-5 IR imagery were analyzed over Northern India, Nepal and the Tibetan Plateau region. These cloud clusters were separated into mesoscale convective complexes (MCCs), smaller but long lived convective cloud clusters (CCSs), and disorganized short-lived convection (DSC). This investigation focuses on the relationship of cloud morphology with landform and orography in this region.

The diurnal march and propagation of patterns of convective activity in the Himalayas and northern Indian subcontinent were examined and their relationships with landform and orography were assessed. Results indicate that infrared satellite images of northern India and along the southern flank of the Himalayas reveal a strong presence of convective weather systems during the monsoon, especially during the afternoon and night. Typical MCCs have life-times of $11 \mathrm{~h}$, and areal extent up to $400000 \mathrm{~km}^{2}$. Although the core of MCC activity remains away from the mountains, the timing of heavy precipitation events is linked to the presence of MCCs, as well as BoB monsoon depressions that venture into the Lesser Himalayan region, and remain within the region bounded by $25-30^{\circ} \mathrm{N}$. One principal feature in the temporal organization of convection is the dichotomy between the Tibetan Plateau and the Northern Indian plains: CCCs and DSCs begin in the Tibetan Plateau in the mid-afternoon into the evening; they are most active at midnight and in the early morning in the Gangetic Plains and along the southernfacing slopes of the Himalayas. Analysis of TRMM data allowed us to identify small-scale precipitation features with areal extent on the order of $100 \mathrm{~s} \mathrm{~km}^{2}$ aligned with ridges and valleys in regions 3,4 and 5 and concentrated at elevations ranging 2000-5000 $\mathrm{m}$. These precipitation features are consistent with shallow embedded convection in reflectivity profiles of the Precipitation Radar on the TRMM satellite, and with raingauge observations that indicate strong differences between the diurnal cycle of rainfall above and below $2000 \mathrm{~m}$ (Fig. 2, Fig. 3, Figs. 9a-d).

Focusing on the dynamic evolution of cloud fields, we found strong, coherent relationship between the predominant modes of space-variability of cloudiness and landform, as modulated by ocean-land-atmosphere interactions and their impact on the succession of active and break phases of the monsoon (Figs. 10, 11, 12 and 13). Furthermore, although the arrangement of cloudiness features vis-a-vis monsoon circulations is consistent with idealized modeling studies of the monsoon, our analysis shows that boundaries and transition areas (e.g. the east-west asymmetry in precipitation) are explicitly associated with orographic features (e.g. the Aravalli-Garwhal topographic divide).

A comparative analysis between the collocated variability of topography and the overlying cloud cover leads us to identify two distinct types of orographic controls at different spatial scales: a synoptic mode $(\sim 300 \mathrm{~km})$ associated with the overall terrain envelope and the major river valleys that cut through the mountains connecting the Indian subcontinent and the Tibetan Plateau; and a second associated with the quasi-periodic succession of ridges and valleys that constitute the Himalayan range $(5-150 \mathrm{~km})$. Depending on the actual complexity of the terrain within different regions in the Himalayan range, we found that the variance of cloudiness and its scaling behavior reflects the ridge density as well as its altitudinal range. Temporal analysis of this behavior indicates that the predominant time-scale is close to 10 days in the early half of the monsoon (June-July) and subsequently increases up to $20+$ days in the recession period (August-September), consistent with the succession of active and break phases.

Overall, the relationships between the space-time variability of cloudiness and regional monsoon dynamics are congruent with precipitation observations, which suggests that skill should be added to monsoon rainfall estimation with knowledge of regional cloud patterns and orography. From a different perspective, the lingering question is whether atmospheric circulations (i.e. climate) or tectonics independently determined the evolution of landform as we see it today, or whether landscape evolution results from two-way 
orographic land-atmosphere interactions leading to mutual adjustment of large-scale circulation and terrain over geological time scales. We are now investigating this mechanism through numerical model simulations.

\section{Appendix A EOF analysis}

Empirical Orthogonal Function (EOF) analysis was conducted to identify dominant modes of spatial variability of cloudiness. To describe the variability, anomalies of the hourly cloudiness fields $s_{t}^{\prime}$ were calculated first:

$s_{t}^{\prime}=s_{t}-\widehat{\mu}$

where $\widehat{\mu}$ is the mean field over the period of analysis. Next, consider the anomalies expressed as a summation of a finite series of independent patterns:

$s_{t}^{\prime}=\sum_{i=1}^{k} \widehat{\alpha}_{i, t} e^{i}$

where $e^{i}$ are the estimated Empirical Orthogonal Functions (EOFs), and $\widehat{\alpha}_{i, t}$ are EOF coefficients (ECs) known as principal components. The EOFs are orthogonal vectors and the lag-0 sample cross-correlations of the ECs are all zero. The ECs can thus be obtained by projecting the anomalies onto the EOFs, and minimizing the squared difference between the right- and left-hand sides of Eq. (A2). This is equivalent to calculating the eigenvalues (ECs) and unit eigenvectors (EOFs) of the covariance matrix of the anomalies. Each eigenvalue (EC) corresponds to the fraction of total variance of the anomaly fields that is described by the corresponding eigenvector (EOF). By convention, the EOFs are ranked according the magnitude of the corresponding $\mathrm{EC}$ values, that is: the first EOF is the eigenvector corresponding to the largest eigenvalue (first EC), the second EOF provides the mode of variability with greatest variance that is not correlated to the first EOF, etc.

\section{Appendix B CC analysis}

Canonical Correlation (CC) analysis allows us to investigate the correlation structure of pairs of random variables $A$ and $B$ in a manner similar to EOF analysis but with the objective of finding the modes of variability $\beta$ (canonical correlation coordinates) that maximize the linear correlation between the two fields of interest. Consider the anomalies of each field expressed as a finite summation of the product of the vector of canonical correlation coordinates normalized to unit variance and the matrix of canonical correlation patterns $f_{A}$ and $f_{B}$ :

$$
\begin{aligned}
& A_{t}^{\prime}=\sum_{i=1}^{k} \beta_{i, t}^{A} f_{A}^{i} \\
& B_{t}^{\prime}=\sum_{i=1}^{k} \beta_{i, t}^{B} f_{B}^{i}
\end{aligned}
$$

where $k$ is the number of correlation pattern being considered, and $t$ is the time at which the anomaly fields were derived. The canonical correlation patterns can be obtained as the orthonormal sets of vectors that maximize the covariance of the canonical coordinates $\operatorname{Cov}\left(\beta_{t}^{A}, \beta_{t}^{B}\right)$ expressed as a function of the covariance matrix of the two fields of interest:

$\operatorname{Cov}\left(\beta_{i}^{A}, \beta_{i}^{B}\right)=\left[f_{A}^{i}\right]^{T} \operatorname{Cov}(A, B)\left[f_{B}^{i}\right]=\lambda_{i}^{1 / 2}$

where

$\left\{\begin{array}{l}\operatorname{Cov}(A, B)\left[f_{B}^{i}\right]=\lambda_{i}^{1 / 2}\left[f_{A}^{i}\right]=\rho\left(\beta_{i}^{A}, \beta_{i}^{B}\right)\left[f_{A}^{i}\right] \\ \operatorname{Cov}(A, B)^{T}\left[f_{A}^{i}\right]=\lambda_{i}^{1 / 2}\left[f_{B}^{i}\right]=\rho\left(\beta_{i}^{A}, \beta_{i}^{B}\right)\left[f_{B}^{i}\right]\end{array}\right.$

The eigenvalues $\lambda_{i}$ represent the squared cross-correlation of the corresponding canonical correlation patterns $\rho\left(\beta_{i}^{A}, \beta_{i}^{B}\right)$. For further details, please see von Storch and Zwiers (1999).

\section{Appendix C Wavelet analysis}

Wavelet analysis is a useful tool to detect predominant modes of variability in non-stationary time series. Like Fourier analysis, wavelet analysis involves representing a time series as an infinite, weighted sum of continuous functions. In the case of Fourier analysis, the functions are infinitely long sine and cosine functions (waves). In the case of wavelet analysis, the functions have nonzero value over a finite length, and are localized in space (wavelets). In practice, the finite-duration functions or wavelets used are only finite in the asymptotic sense. In our applications, we used the Morlet wavelet, a plane wave modulated by a Gaussian, which is asymptotic to zero:

$\Psi_{0}(\eta)=\pi^{-1 / 4} \times e^{i \omega_{0} \eta} \times e^{-\eta^{2} / 2}$

where $\eta$ is a non-dimensional time index and $\omega_{0}$ is the non-dimensional frequency. Given a time-series $f_{x}(m)$ with $N$ values at equal time intervals $\delta t[m=0, \ldots, N-1]$, the wavelet transform is the convolution of $f_{x}$ with the wavelet function $\Psi_{0}$ :

$W_{n}(s)=\sum_{j=0}^{N-1} f_{x}(j) \Psi_{0}^{*}\left[\frac{(j-n) \delta t}{s}\right]$

where $s$ is the wavelet scale (duration length), $\Psi_{0}^{*}$ is the conjugate of $\Psi_{0}$, and $n$ is the number of intervals by which the origin of the wavelet function is translated. The wavelet scale replaces the concept of periodicity in the case of Fourier analysis by the temporal scale. The equivalent of low frequencies (long periods) are obtained by stretching the length of the wavelet (long time scales), and high frequencies (short periods) are obtained by contracting the length of the wavelet (short time scales). At each point in time, the time series is then approximated as a sum of wavelets at different scales. The method used here to compute the wavelet transforms and determine the important time scales is that described by Torrence and Compo (1998), and we used a version of their algorithm for both calculations and graphical display. 
The wavelet spectrum or modulus is defined as $\left|W_{n}(s)\right|^{2}$. This corresponds to a 3-D surface as a function of time (location $n$ ), time-scale $(s)$ and amplitude (coefficient) of the wavelet. Similar to the Fourier power spectrum, a high value of the coefficient indicates that there is a strong contribution by that scale of wavelet at that time. The width of an area of high contribution indicates the time period during which the contribution of that temporal scale is relevant. The height of the area indicates how well resolved the contribution is in a manner similar to the width of individual peaks in the Fourier spectrum. That is, well-resolved time scales should correspond to very narrow heights in the graph of the wavelet modulus. Depending on the duration of the time series that are portions of the wavelet modulus that cannot be estimated with a high confidence level. Specifically, at both ends of the time series and for very long time scales, which require long periods of observation as per the requirements of the sampling theorem. These regions are delineated with a line corresponding to a $95 \%$ confidence level in our plots.

\section{Appendix D Empirical scaling analysis}

In the general context of simple scaling, the relationship between the statistical moment of order $h$ of cloud fields $\left(m_{h}(\lambda)=E\left[S_{\lambda}^{h}\right]\right)$ and spatial scale $\lambda$ is linear in log-log space:

$\log \left[m_{h}(\lambda)\right]=s(h) \log \lambda+\log \left[m_{h}(1)\right]$

Moreover, the relationship between $h$ and $s(h)$, the scaling exponent for the statistical moment of order $h$, is linear. In the case of the variance, $h=2$. For further details, please see Gupta and Waymire (1990).

A variogram is a plot of the variance of a time series against the aggregation scales. To compute the variogram, new sequences at increasingly coarser spatial scales are generated from the original cloud series by averaging. The variances are then plotted against the equivalent scale corresponding on a log-log plot to examine the scaling behavior. Assuming that the variogram corresponds to a power law, the scaling behavior of the data can be described via the Hurst exponent, which corresponds to one half of the slope of the power law in the log-log plot of the variance versus the spatial scale $(\log ($ variance $)=$ constant $-2 \mathrm{H} \times \log ($ spatial - scale $))$, and is closely related to the fractal dimension $D(D=2 H)$. When the slope of the variogram changes between different ranges of spatial scales, and thus the Hurst coefficient and the fractal dimension, the data exhibit multiscaling behavior. Scale break points are the spatial scales where changes in slope occur. In principle, multiscaling is consistent with changes in the underlying spatial variability of the data in response to changes in governing physics. Therefore, changes of the fractal dimension with time suggest that multifractality and multiscaling are mutually influential in determining the space-time structure of cloud fields. The empirical scaling analysis and application of fractal formalism used here is based on Hastings and Sugihara (1993).

Acknowledgements. This research was funded in part by NASAGSFC under Grant NAG5-9823 and NSF EAR-9909498. We are thankful to our colleagues D. Burbank, R. Carbonne, T. Lang and E. J. Zipser for many insightful discussions and suggestions. S. W. Nesbitt acknowledges the support of the NASA Earth System Science Graduate Fellowship Grant NGT5-30423.

Edited by: F. Castelli

Reviewed by: two referees

\section{References}

Augustine, J. A. and Howard, K. W.: Mesoscale convective complexes over the United States during 1986 and 1987, Mon. Wea. Rev., 119, 1575-1589, 1991.

Barros, A. P. and Lang, T.: Monitoring the monsoon in the Himalayas: observations in central Nepal, June 2001, Mon. Wea. Rev., 131., 1408-1427, 2003a.

Barros, A. P. and Lang, T.: Exploring Spatial Modes of Variability of Terrain-Atmosphere Interactions in the Himalayas During Monsoon Onset. Hydrosciences Report Series 03-001, Environmental Sciences and Engineering Program, Division of Engineering and Applied Sciences, Harvard University, 51, $2003 \mathrm{~b}$.

Barros, A. P., Joshi, M., Putkonen, J., and Burbank, D. W.: A study of the 1999 monsoon rainfall in a mountainous region in central Nepal using TRMM products and rain gauge observations, Geophy. Res. Lett., 27(22), 3683-3686, 2000.

Chou, C., Neelin, J. D., and Su, H.: Ocean-atmosphere-land feedbacks in an idealized monsoon, Quart. J. Roy. Met. Soc., 127, 1869-1891, 2001.

Christian, H. J., Blakeslee, R. J., Goodman, S. J., Mach, D. A., Stewart, M. F., Buechler, D. E., Koshak, W. J., Hall, J. M., Boeck, W. L., Driscoll, K. T., and Bocippio, D. J.: The Lightning Imaging Sensor, Proceedings of the 11th International Conference on Atmospheric Electricity, Guntersville, Alabama, June 17-11, 746-749, 1999.

D'Amato, N. and Lebel, T.: On the characteristics of the rainfall events in the Sahel with a view to the analysis of climate variability, Int. J. Clim., 18, 955-974, 1998.

Evans, J. L. and Shemo, R. E.: A procedure for automated satellitebased identification and climatology development of various classes of organized convection, J. Appl. Meteor., 35, 638-652, 1996.

Fabry, F.: On the determination of scale ranges for precipitation fields, J. Geophysical Res., 101, 12 819-12 826, 1996.

Feijt, A. and Jonker, H.: Comparison of scaling parameters from spatial and temporal distributions of cloud properties, J. Geophysical Res., 105, 29 089-29 097, 2000.

Fritsch, J. M. and Maddox, R. A.: Convective driven mesoscale pressure systems aloft. Part 1: Observations, J. Appl. Meteor., 20, 9-19, 1981.

Hahn, D. G. and Manabe, S.: The role of Mountains in the South Asian Monsoon Circulation, J. Atmos. Sci., 32, 1515-1541, 1975.

Hastings, H. M. and Sugihara, G.: Fractals: A User's Guide for the Natural Sciences, Oxford Science Publications, Oxford, New York, Tokyo, 1994. 
Hodges, K. I. and Thorncroft, C. D.: Distribution and statistics of African mesoscale convective weather systems based on the ISCCP Meteosat imagery, Mon. Wea. Rev., 125, 2821-2837, 1997.

Krishnamurti, T. N. and Kishtawal, C. M.: A pronounced continental-scale diurnal mode of the Asian summer monsoon, Mon. Wea. Rev., 128, 462-473, 2000.

Kim, G. and Barros, A. P.: Downscaling of remotely sensed soil moisture with a modified fractal interpolation method using contraction mapping and ancillary data, Remote Sensing of the Environment, 83, 400-413, 2002.

Kim, G., and Barros, A. P.: Space-time characterization of soil moisture from passive microwave remotely sensed imagery and ancillary data, Remote Sensing of the Environment, 81, 1-11, 2002.

Laing, A. G. and Fritsch, J. M.: The global population of mesoscale convective complexes, Q. J. R. Meteorol. Soc., 123, 389-405, 1997.

Lang, T. and Barros, A. P.: An investigation of the onsets of the 1999 and 2000 monsoons in Central Nepal, Mon. Wea. Rev., 130, 1299-1316, 2002.

Laing, A. G. and Fritsch, J. M.: The global population of mesoscale convective complexes, Q. J. R. Meteorol. Soc., 123, 389-405, 1997.

Maddox, R. A.: Mesoscale convective complexes, Bull. Am. Meteorol. Soc., 61(11), 1374-1387, 1980.

Mathon, V. and Laurent H.: Life cycle of Sahelian mesoscale convective cloud systems, S. J. R. Meteorol. Soc., 127, 377-406, 2001.

Mcanelly, R. L. and Cotton, W. R.: The precipitation life cycle of mesoscale convective complexes over the central United States, Mon. Wea. Rev., 117, 784-808, 1989.

Nesbitt, S. W., Zipser, E. J., and Cecil, D. J.: A Census of precipitation features in the tropics using TRMM: radar, ice scattering, and lightning observations, J. Climate, 13, 4087-4106, 2000.

Murakami, M.: Analysis of the deep convective activity over the western Pacific and Southeast Asia, Part I: Diurnal variation, J. Meteor. Soc. Japan, 61, 60-77, 1983.
Murakami, M.: Orography and Monsoons, Monsoon Meteorology, edited by Chang, C.-P. and Krishnamurti, T. N., Oxford University Press (Pub.), 331-364, 1987.

Petersen, W. A., Rutledge, R. A., Orville, R. E.: Cloud-to-Ground Lightning Observations from TOGA-COARE: Selected Results and Lightning Location Algorithms, Mon. Wea. Rev., 124, 602620, 1996.

Rodwell, M. J. and Hoskins, B. J.: Monsoons and the dynamics of deserts, Q. J. R. Meteorol. Soc., 122, 1385-1404, 1996.

Rossow, W. B.: Measuring cloud properties from space: A review, J. Climate, 2, 201-213, 1989.

Tessier, Y., Lovejoy, S., and Schertzer, D.: Universal multifractals: Theory and observations for rain and clouds, J. of Appl. Meteorology, 32, 223-237, 1993.

Torrence, C. and Compo, G. P.: A practical guide to wavelet analysis, Bulletin of the Am. Meteorol. Soc., 79, 61-78, 1998.

Vechi, G. A. and Harrison, D. E.: Monsoon breaks and subseasonal sea surface temperature variability in the Bay of Bengal, J. Climate, 15 (12), 1485-1493, 2002.

Veneziano, D. and Iacobellis, V.: Self-similarity and multifractality of topographic surfaces at basin and subbasin scales, J. of Geoph. Res., 104, 12 797-12 812, 1999.

Von Storch, H. and Zwiers, F. W.: Statistical analysis in climate research, Cambridge University Press, 455, 1999.

Webster, P. J., Magaña, V. O., Palmer, T. N., Shukla, J., Tomas, R. A., Yanai, M., and Yasunari, T.: Monsoons: Processes, predictability, and the prospects for prediction, J. Geoph. Res., 103, 14 451-14 510, 1998.

Webster, P. J.: The variable and interactive Monsoon, Monsoon Meteorology, edited by Chang, C.-P. and Krishnamurti, T. N., Oxford University Press (Pub.), 269-329, 1987.

Williams, M. and Houze Jr., R. A.: Satellite observed characteristics of winter monsoon cloud clusters, Mon. Wea. Rev., 115, 505519, 1987.

Wilks, D. J.: Statistical methods in the Atmospheric Sciences, Academic Press (Pub.), 464, 1995.

Xie, S.-P. and Saiki, N.: Abrupt onset and slow seasonal evolution of the summer Monsoon in an idealized GCM simulation, J. Meteo. Soc. Jap., 77, 949-968, 1999. 